\title{
Human FcRn expression and Type I Interferon signaling control Echovirus 11 pathogenesis in mice
}

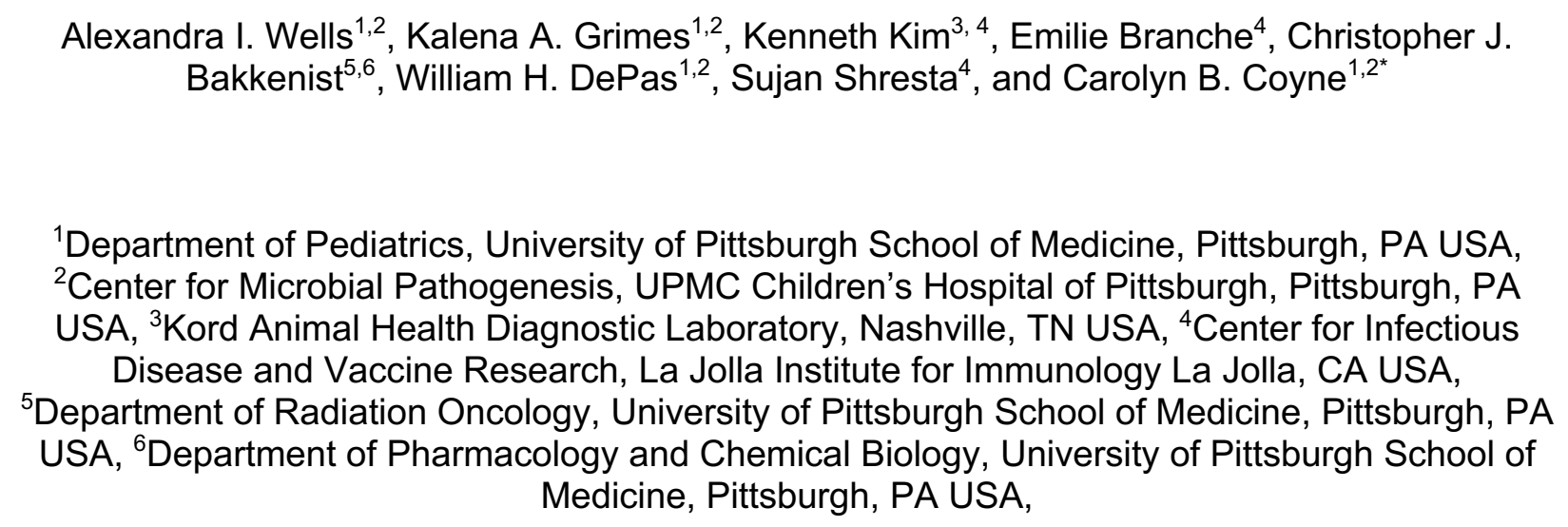




\section{Abstract}

Neonatal echovirus infections are characterized by severe hepatitis and neurological

complications that can be fatal. Here, we show that expression of the human homologue of the neonatal Fc receptor (hFcRn), the primary receptor for echoviruses, and ablation of type I interferon (IFN) signaling are key host determinants involved in echovirus pathogenesis. We show that expression of $\mathrm{hFcRn}$ alone is insufficient to confer susceptibility to echovirus infections in mice. However, expression of hFcRn in mice deficient in type I interferon (IFN) signaling, hFcRn$\mathrm{IFNAR}^{-/-}$, recapitulate the echovirus pathogenesis observed in humans. Luminex-based multianalyte profiling from E11 infected $\mathrm{hFcRn-IFNAR}{ }^{-/-}$mice revealed a robust systemic immune response to infection, including the induction of type I IFNs. Furthermore, similar to the severe hepatitis observed in humans, E11 infection in hFcRn-IFNAR ${ }^{-/-}$mice caused profound liver damage. Our findings define the host factors involved in echovirus pathogenesis and establish in vivo models that recapitulate echovirus disease.

\section{Introduction}

67 Echoviruses are small $(\sim 30 \mathrm{~nm})$ single-stranded RNA viruses that belong to the Picornaviridae

68 family. Echoviruses consist of approximately 30 serotypes and are members of the Enterovirus genus, which are primarily transmitted through the fecal-oral route. Infants and neonates are often most severely impacted by echovirus infections, with the majority of enterovirus infections in

71 infants below the age of two months caused by echoviruses ${ }^{1,2}$. Echovirus infections are 72 particularly devastating in Neonatal Intensive Care Unit (NICU) outbreaks, where they account

73 for $15-30 \%$ of nosocomial viral infections and can result in death of the neonate in as many as

$7425 \%$ of $\operatorname{cases}^{3-6}$. Echovirus $11(\mathrm{E} 11)$ is one of the most common serotypes associated with

75 outbreaks in NICUs across the world ${ }^{7,8}$. Despite the severe clinical outcomes associated with

76 echovirus infections, the tissue tropism and pathogenesis of infection remain largely unknown 
77 due to the lack of established animal models to study E11 infection at secondary sites of infection,

78 such as the liver and brain.

79 We and others previously identified the neonatal Fc receptor (FcRn) as a primary receptor for 80 echoviruses $^{9,10}$. Structural analysis has shown that the murine homologue of FcRn $(\mathrm{mFcRn})$ does

81 not support echovirus binding and entry ${ }^{10}$, which has also been shown experimentally in murine-

82 derived primary cells and cell lines ${ }^{9}$. However, ectopic expression of human FcRn (hFcRn)

83 renders murine-derived primary cells susceptible to echovirus infections ${ }^{9}$. FcRn is important for

84 establishing passive immunity from mother to child through IgG transport across the placenta

85 during human pregnancy or across the small intestine after birth in mice ${ }^{11}$. Additionally, FcRn is

86 important for albumin homeostasis in liver hepatocytes and regulates the response to hepatic

87 injury ${ }^{12}$. FcRn expression is maintained throughout life in the liver and many other tissue types in

88 the body ${ }^{13}$. We have previously demonstrated in an oral infection model of suckling mice that E11

89 disseminates from the gastrointestinal $(\mathrm{GI})$ tract into the blood and liver, and that this

90 dissemination is dependent on the expression of human $\mathrm{FcRn}^{9}$. Although the virus disseminated

91 to the liver, very little detectable virus was observed in this and other tissues, occluding further

92 studies of pathogenesis at secondary sites of infection.

93 The development of mouse models that recapitulate the hallmarks of enterovirus disease in

94 humans has historically been challenging. Enteroviruses typically do not infect mice as the murine

95 homolog of their receptors are often not sufficient for binding and entry. Others have developed

96 mouse models of select enteroviruses including poliovirus, coxsackievirus B (CVB), and

97 enterovirus $71(\mathrm{EV} 71)^{14-16}$. These models often use immunodeficient humanized transgenic mice,

98 which express the human homolog of the receptor while lacking expression of the interferon $\alpha / \beta$

99 receptor (IFNAR) ${ }^{15-19}$. Despite established in vivo models for other enteroviruses, echoviruses

100 have few established mouse models. A previous echovirus 1 mouse model was established using

101 transgenic mice expressing human integrin very late antigen 2 (VLA-2), the receptor for $E 1^{20}$,

102 which inoculated newborn mice intracerebrally, resulting in paralysis of the transgenic mice ${ }^{21}$. 
However, the host determinants involved in restricting echovirus infections in vivo remain largely

104 unknown.

105 Here, we define the host determinants of echovirus infection and developed parallel adult and 106 suckling mouse models of E11 infection. We show that immunocompetent animals that express $107 \mathrm{hFcRn}$ under the native human promotor $\left(\mathrm{hFcRn}{ }^{T g 32}\right)$ are largely resistant to $\mathrm{E} 11$ infection 108 following intraperitoneal (IP) inoculation. In addition, immunodeficient mice lacking IFNAR expression (IFNAR ${ }^{-/}$) alone are also refractory to infection. In contrast, $\mathrm{hFcRn}{ }^{\top \mathrm{g} 32}$ animals that are also deficient in IFNAR expression $\left(\mathrm{hFCRn}^{\mathrm{Tg} 32}\right.$ IFNAR $^{-/-}$) are highly permissive to $\mathrm{E} 11$ infection and high levels of viral replication occur in the liver and pancreas, which reflects the tissue sites most commonly targeted in infected human neonates ${ }^{22,23}$. Luminex-based multianalyte profiling

113 of whole blood revealed that $\mathrm{hFCRn}{ }^{T g 32}$-IFNAR ${ }^{-/-}$infected animals induced a robust systemic 114 immune response to infection, including high levels of type I IFNs. Using RNASeq-based 115 transcriptional profiling, we also show that the livers of $\mathrm{hFcRn}{ }^{T g 32}$-IFNAR ${ }^{-/-}$mice mount a pro116 inflammatory and antiviral signaling cascade in response to infection. Finally, using hybridization 117 chain reaction (HCR) with specific probes against the E11 genome, we show that hepatocytes 118 are the main cell type infected in the liver. Our data thus define hFcRn and type I IFN signaling 119 as key host determinant of E11 pathogenesis in the liver and suggest that these factors could be 120 targeted therapeutically to control infection.

122 Results

\section{Human FcRn and Type I IFN signaling are key host determinants of E11 infection}

124 Given that the most severe outcomes of E11 infections in humans are in neonates, we first 125 performed studies in suckling ( 7 day old) mice. We inoculated immunocompetent wild-type 126 C57BL/6 (WT) and hFcRn ${ }^{\top 932}$ suckling mice with $10^{4}$ plaque forming units (PFU) of E11 by the IP 127 route. Animals were sacrificed at 72 hours post inoculation (hpi) and tissues were collected for 128 viral titration by plaque assay. Because an IP echovirus mouse model has not been established 
previously, we collected a diverse range of tissues (e.g. brain, liver, pancreas, small intestine) to determine the tissue tropism of $\mathrm{E} 11$ in vivo. WT and $\mathrm{hFcRn}{ }^{\top \mathrm{g} 32}$ animals exhibited low to undetectable levels of infection in all of the tissues tested (Figure 1A-F). For example, only 2 of 12 WT animals and 2 of $13 \mathrm{hFcRn}{ }^{\text {Tg32 }}$ animals had any detectable virus in liver and 0 of 12 WT mice and 1 of $13 \mathrm{hFcRn}{ }^{\mathrm{Tg} 32}$ mice had detectable virus in the brain, although in both cases, viral

134 titers were very low (Figure 1B, 1F). Because many enteroviruses are restricted by type I IFN 135 signaling in small animal models and because we have previously shown that E11 is sensitive to recombinant IFN- $\beta$ treatment ${ }^{24}$, we reasoned that type I IFNs might play a key role in restricting E11 infection in vivo. To test this, we infected suckling mice deficient in type I IFN signaling $\left(\mathrm{IFNAR}^{-/-}\right)$with $10^{4}$ PFU E11 by the IP route. However, we found that these animals were also largely resistant to E11 infection, with most animals having no detectable circulating virus in blood or replicating virus in tissues (4 of 12 animals had detectable virus in the blood and liver) (Figure 1A-F). These data show that expression of hFcRn or ablation of type I IFN signaling alone is insufficient to confer susceptibility to E11 replication.

We next determined whether expression of $\mathrm{hFcRn}$ in the context of ablation of IFNARmediated signaling would be sufficient for E11 infection in mice. To do this, we generated $145 \mathrm{hFcRn}{ }^{T g 32}$ mice that are deficient in IFNAR expression $\left(\mathrm{hFcRn}{ }^{\mathrm{Tg} 32}\right.$-IFNAR $\left.{ }^{-/-}\right)$. Similar to the studies 146 described above, we inoculated suckling hFcRn ${ }^{T g 32}$-IFNAR ${ }^{-/-}$mice with $\mathrm{E} 11$ by IP inoculation. In 147 contrast to animals expressing hFcRn or lacking IFNAR expression alone, we found that $148 \mathrm{hFcRn}{ }^{\text {Tg32 }}$ IFNAR $^{-/-}$suckling mice were highly permissive to E11 infection, with high levels of 149 infectious virus circulating in blood (17 of 18 animals, Figure 1A). Similarly, hFcRn ${ }^{T g 32}$ IFNAR $^{-/-}$ animals had significantly more detectable infectious virus in livers compared to other genotypes 151 (18 of 18 with detectable virus in liver) (Figure 1B). In addition to liver, we also observed high viral loads in the pancreas of hFcRn ${ }^{T g 32}$-IFNAR ${ }^{-/-}$animals (18 of 18 with detectable virus, Figure

153 1C). We also observed increased viral titers in the stool, small intestine, and brain, which all contained moderate to high levels of viral infection in $\mathrm{hFcRn}{ }^{\top g 32}$-IFNAR ${ }^{-/-}$mice (Figure 1D-F). 
155 These results show that $\mathrm{hFCRn}{ }^{\text {Tg32-IFNAR }}{ }^{-/-}$suckling mice are highly permissive to E11 156 inoculation.

157 We next determined whether $\mathrm{hFcRn}$ and IFN signaling played a role in echovirus 158 pathogenesis in adult (6-week-old) mice. Similar to our findings in suckling mice, we found that $159 \mathrm{WT}, \mathrm{hFcRn}{ }^{\mathrm{Tg} 32}$, and IFNAR ${ }^{-/-}$mice were largely resistant to $\mathrm{E} 11$ infection (Figure 2A-F). In

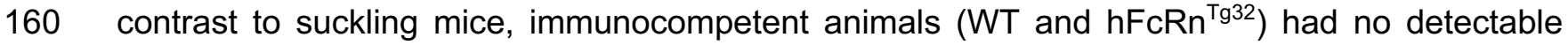
161 circulating virus and a majority of IFNAR ${ }^{-/-}$animals also completely resisted infection (2 of 16 with detectable virus in the blood) (Figure 2A). In contrast, hFcRn ${ }^{T g 32}$-IFNAR ${ }^{-/-}$animals had significant levels of viral replication in the blood (12 of 23 with detectable virus), liver (20 of 23 with detectable virus) and pancreas (13 of 23 with detectable virus), similar to what was observed in suckling

pups (Figure 2A-C). Additionally, these animals had low levels of detectable virus in the stool and small intestine suggesting this is not a main site of replication following IP inoculation (Figure 2D

\& 2E). In contrast to suckling mice, adult $h F c n^{T g 32}$-IFNAR ${ }^{-/-}$animals did not contain high levels adult and suckling mice (Figure 2F). Taken together, these data show that both hFcRn and type I IFNs are key regulators of E11 infection of suckling mice and adult mice and that the liver is a 171 key target site of replication in vivo.

175 Due to the high levels of viremia in adult $\mathrm{hFcRn}{ }^{\mathrm{Tg} 32}$-IFNAR ${ }^{-/-}$mice, we next characterized the 176 systemic immune response to E11 infection in these animals. To do this, we performed Luminex177 based multiplex assays to assess the levels of 45 circulating cytokines and chemokines in the 178 blood of adult animals infected with E11. Consistent with their low levels of infection, we observed 179 no significant changes in the levels of circulating cytokines and chemokines in immunocompetent 180 (WT, hFcRn ${ }^{\top \mathrm{g} 32}$ ) or immunodeficient (IFNAR ${ }^{--}$) mice (Figure 3A). In contrast, the blood of infected 
$\mathrm{hFCRn}{ }^{\mathrm{Tg} 32}$-IFNAR ${ }^{-/-}$animals contained high levels of various cytokines and chemokines in

response to infection, with 19 cytokines/chemokines induced $\geq 2$-fold compared to uninfected

controls (Figure 3A). The two most induced cytokines were members of the type I IFN family,

IFN- $\alpha$ and IFN- $\beta$. On average, $7,802 \mathrm{pg} / \mathrm{mL}$ of IFN- $\beta$ was circulating in the blood of $\mathrm{hFcRn}{ }^{\top g} 32$ -

IFNAR $^{-/-}$animals, while WT, hFcRn ${ }^{\text {Tg32 }}$, and IFNAR ${ }^{-/-}$animals had little to no circulating IFN- $\beta$

(Figure 3B). Similarly, hFcRn ${ }^{T g 32}-$ IFNAR $^{-/-}$animals had an average of $165 \mathrm{pg} / \mathrm{mL}$ circulating IFN-

3C). In addition to type I IFN induction, a number of chemokines, including monocyte chemoattractant protein 1 (MCP-1/CCL2), B cell attracting chemokine 1 (BCA-1/CXCL13), IP10/CXCL10, and IL-12(p40) were present at very high levels in E11 infected hFcRn ${ }^{\top 932}$ IFNAR $^{-/-}$ mice (Figure 3D-G). These data show adult hFcRn ${ }^{T g} 32-I F N A R^{-/}$animals mount a potent immune response, including very high levels of type I IFNs, in response to E11 infection.

\section{Infection and immune responses peak at $72 \mathrm{~h}$ post-inoculation}

Next, we determined the kinetics of the immune responses to E11 infection in hFcRn ${ }^{T g 32}$-IFNAR $^{-}$

I- mice. To do this, we infected $\mathrm{hFcRn}{ }^{\mathrm{Tg} 32}$ IFNAR $^{-/}$animals with $\mathrm{E} 11$ and sacrificed at either 24,

48, or $72 \mathrm{hpi}$ and measured viral titers by plaque assays and immune induction by Luminex-based multiplex assays for 34 cytokines and chemokines. We found that there were measurable levels of virus present in key target tissues such as the blood, liver and pancreas by as early as $24 \mathrm{hpi}$,

200 with levels peaking at 72hpi (Figure 4A-D). Consistent with these kinetics, we found that the 201 levels of circulating cytokines increased at $24 \mathrm{hpi}$ and peaked at $72 \mathrm{hpi}$ as assessed by multianalyte 202 Luminex-based profiling (Figure 4E). Strikingly, IFN- $\beta$ was induced over $\sim 1,000 \mathrm{pg} / \mathrm{mL}$ in animals 203 infected for $24 \mathrm{hrs}$ and even higher in animals after 48hpi and 72hpi (Figure 4F). In addition, IFN$204 \alpha$ and IFN- $\lambda 2 / 3$ were increased at 72hpi compared to control and $24 \mathrm{hpi}$ (Figure 4 G \& $4 \mathrm{H}$ ). In 205 contrast to IFNs, other cytokines and chemokines including IP-10/CXCL10, MCP-1/CCL2, and 
$\mathrm{KC/CXCL1}$ were induced at highest levels at 48hpi, with levels decreasing by $72 \mathrm{hpi}$ (Figure 4I-

K). These data suggest that animals induce an immune response to infection very early following

208 the initiation of viral replication.

\section{E11 infection induces damage and cell death in the livers of $h F c \mathrm{Rn}^{\mathrm{Tg} 32}{ }_{\text {-IFNAR }}{ }^{-/-}$animals}

211 Echovirus infections in neonates commonly induces liver failure, which can be fatal ${ }^{23}$. In addition, 212 our data suggested that the highest levels of $\mathrm{E} 11$ replication in $\mathrm{hFcRn^{ \top g } 3 2}{ }^{-I F N A R^{-/-}}$mice was in 213 the liver. Thus, we focused on the impact of E11 infection on the liver as a contributor to disease.

214 Blinded pathology scoring of H\&E stained sections of infected livers revealed no histopathologic changes in immunocompetent animals or in IFNAR ${ }^{-/-}$adult or suckling mice infected with E11

(Figure 5A-B, Supplemental Figure 1). In contrast, there was moderate to severe liver damage

217 induced by E11 infection of adult $\mathrm{hFcRn}^{\mathrm{Tg} 32}$-IFNAR ${ }^{-/-}$animals, including punctate hepatocytolysis

218 and necrosis at 72hpi (Figure 5A, Supplemental Figure 1). Other histopathological changes

219 included increased immune cell infiltration, which was also observed in infected $\mathrm{hFcRn}^{\text {Tg32 }}$-IFNAR $^{-}$

$220{ }^{\text {I- }}$ suckling mice (Figure 5B, black arrows). In addition to histopathology, we assessed the impact

221 of infection on cell viability using an antibody specific for the cleaved (activated) version of

222 caspase-3. Whereas E11 infection of immunocompetent and IFNAR ${ }^{-/-}$animals exhibited no

223 cleaved caspase-3 staining as assessed by immunohistochemistry, E11-infected hFcRn ${ }^{T g 32}$.

224 IFNAR $^{-/}$adults and suckling mice exhibited pronounced positive cleaved caspase-3 staining

225 (Figure 5C, 5D). These data indicate that the livers of $h F c R n^{\top g 32}-I F N A R^{-/}$animals undergo 226 apoptosis and cell death following E11 infection.

228 E11 infection of $\mathrm{hFcRn}{ }^{\mathrm{Tg} 32}$-IFNAR ${ }^{-/-}$mice induces a robust local proinflammatory immune 229 response in the liver

230 Because we found that the livers of $\mathrm{hFCRn}^{\text {Tg32 }}{ }_{\text {IFNAR }}^{-{ }^{-}-}$mice infected with $\mathrm{E} 11$ exhibited 231 histopathologic changes and underwent cell death, we profiled other liver changes by RNAseq 
232 transcriptional profiling. Consistent with our Luminex-based profiling studies of circulating

233 cytokines, we found that the livers of $\mathrm{hFCRn}^{\mathrm{Tg} 32}$-IFNAR ${ }^{-/-}$animals infected with E11 robustly

234 induced expression of the transcripts for type I IFNs, with less robust induction of type III IFNs

235 (Figure 6A). Levels of vRNA in infected animals mirrored our findings on infectious viral titers, 236 with high levels in $\mathrm{hFcRn}{ }^{T g 32}-\mathrm{IFNAR}^{-/-}$mice (Figure 6B). In addition to these changes, $\mathrm{hFcRn}^{\mathrm{Tg} 32}{ }_{-}$ 237 IFNAR $^{-/-}$infected animals also induced the expression of other pro-inflammatory and 238 immunomodulatory factors, including chemokines (e.g. Ccl2, Cxcl1, Cxcl9), transcription factors 239 (e.g. Stat1, Stat3, Socs1), and interferon stimulated genes (e.g. Isg15, Ifit1) (Figure 6C, D).

\section{E11 specifically infects hepatocytes in hFcRn ${ }^{\text {Tg32-IFNAR }}{ }^{-1-}$ mice}

242 Finally, we defined the cellular tropism of E11 within the liver. Using immunohistochemistry for 243 the viral VP1 capsid protein, we found that E11 localized primarily in what appeared to be 244 hepatocytes (Figure 7A). No positive staining for VP1 was observed in any other three mouse 245 strains (Figure 7A). hFcRn ${ }^{\text {Tg32-IFNAR }}{ }^{-/-}$suckling mice also displayed positive VP1 staining in the 246 liver (Supplemental Figure 2). Although VP1 staining suggested that E11 replication occurred 247 primarily in hepatocytes, we developed a more sensitive approach to define the cellular tropism 248 of E11 using hybridization chain reaction (HCRv3.0). HCR allows for multiplexed quantitative RNA 249 fluorescence in situ hybridization (RNA-FISH) and the signal amplification inherent to the 250 technique vastly enhances the dynamic range and sensitivity of conventional FISH-based 251 approaches ${ }^{25-27}$. To do this, we designed probes specific for the E11 genome and performed HCR 252 on liver sections from hFcRn ${ }^{T g} 32-I F N A R^{-/-}$mice infected with E11 (schematic, Figure 7B). To 253 define the localization of E11 specifically to hepatocytes, we also developed probes to albumin, 254 a specific marker of hepatocytes. Using HCR, we observed the presence of E11 vRNA in the 255 livers of infected mice by $24 \mathrm{hpi}$, with the numbers of positive cells increasing by $48-72 \mathrm{hpi}$ (Figure 256 7C). Interestingly, E11 vRNA positive cells exclusively colocalized with albumin, identifying 257 hepatocytes as the main cellular target of infection in the liver. To confirm this, we quantified three 
fields at each time point and quantified colocalization between vRNA and albumin signals, which revealed a strong colocalization (Pearson's coefficient 24hpi $-0.73,48 \mathrm{hrs}-0.85,72 \mathrm{hpi}-0.84$ ). Together, these data show that E11 replicates in liver hepatocytes in $\mathrm{hFcRn}{ }^{\text {Tg32-IFNAR }}{ }^{-/-}$animals.

\section{Discussion}

263 Here, we show that human FcRn and type I IFN signaling are key host determinants that control 264 E11 infection in the liver, a tissue site commonly associated with human disease. Through Luminex-based multianalyte and RNASeq-based transcriptional profiling, we also show that animals expressing $\mathrm{hFcRn}$ and ablated in type I IFN signaling initiate a systemic immune response to infection. Furthermore, we show that E11 replication in the liver induces histopathological changes and apoptotic cell death in hepatocytes. Our findings thus define proviral (hFcRn) and antiviral (type I IFN) host factors that control echovirus infections specifically in the liver. In addition, our studies provide a novel animal model that can be used to test anti271 echovirus therapeutics.

272 Although FcRn has been identified as a pan-echovirus receptor ${ }^{9,10}$, its role in mediating 273 echovirus pathogenesis has remained unclear. Previous work has shown that FcRn is expressed 274 in many different cell types in the body, including the small intestine ${ }^{28,29}$ and in liver 275 hepatocytes ${ }^{30,31}$. Despite what its name implies, FcRn is expressed on many cells throughout life, 276 often at very high levels. Our results shown here define the organs targeted by E11 in an in vivo 277 model, with high levels of replication in various tissues, such as the liver and pancreas. Our 278 parallel adult and suckling pup models allowed us to compare age-related differences that might 279 impact sensitivity or responses to echovirus infections. Of note, the animals used in our studies 280 express hFcRn under the control of the endogenous promoter, which might mimic age-related 281 changes in expression observed in humans. Interestingly, although we detected high levels of 282 echovirus replication in similar tissues between adults and suckling pups, there were age-related 283 differences in viral infection in the brains of these mice. Whereas 16 of 18 of infected $\mathrm{hFcRn}^{\mathrm{Tg} 32}$ 
284 IFNAR $^{-/}$suckling mice exhibited replication in the brain, only 3 of 23 adult animals did. Although

285 this could be attributed to differences on the relative ratio of weight to viral inoculum, circulating

286 viral titers in the blood were similar between suckling pups and adult mice. Given that echovirus

287 infections are commonly associated with aseptic meningitis in neonates, these findings suggest

288 that expression levels of hFcRn and type I IFN signaling could be key determinants of age-related

289 susceptibility in key sites targeted in humans, such as the liver and brain.

290 The liver is a primary site of echovirus-associated disease, with hepatitis and acute liver failure

291 commonly observed in infected infants and children and the majority of echovirus-associated

292 death in neonates occurs due to overwhelming liver failure ${ }^{32}$. Our in vivo findings suggest that

293 FcRn expression is required for this infection only when host type I IFN signaling is ablated. In

294 addition to IFNs, we observed induction of a number of other immunomodulatory factors in

295 infected animals. The role of cytokines in echovirus pathogenesis in humans is not known.

296 However, immunodeficient individuals, including adults, are more susceptible to echovirus

297 infections, which often induces hepatitis ${ }^{33-36}$. In addition, analysis of mutations in the E11 genome

298 induced by selective pressure in an immunodeficient individual who developed chronic infection

299 revealed strikingly high sequence conservation in the 3C virally-encoded protease which often

300 attenuates host cell innate immune signaling ${ }^{36}$. Our studies suggest that type I IFNs are the

301 primary drivers of resistance to echovirus infections in the liver, which is supported by our

302 RNASeq studies, in which low levels of the transcripts for type III IFNs were upregulated by

303 infection. These findings are similar to those for the related enterovirus coxsackievirus B3 (CVB3),

304 whose infection in the liver is also regulated primarily by type I IFN signaling ${ }^{19}$. Collectively, our

305 studies show that expression of $\mathrm{hFcRn}$ in the setting of diminished type I IFN signaling is the 306 primary driver of E11 infection in the liver.

307 Despite the clear hepatic tropism of echoviruses, little is known regarding the cell type(s) 308 targeted by echoviruses in the liver or how these cells respond to infection. Moreover, the role of 309 FcRn in mediating this tropism is unknown. The liver is composed of diverse cell types. In addition 
310 to hepatocytes, which comprise $\sim 80 \%$ of total liver cells, tissue resident Kupffer Cells represent $311 \sim 35 \%$ and liver sinusoidal endothelial cells comprise $\sim 50 \%$ of non-parenchymal cells. FcRn is 312 thought to be expressed in all of these cell types ${ }^{37}$. Our studies thus define the tropism of 313 echoviruses specifically to hepatocytes and show that FcRn expression is a key determinant of 314 this tropism. In addition, our studies suggest that echovirus infection of hepatocytes induces 315 pronounced hepatic damage, characterized by apoptotic cell death and tissue damage. These 316 findings are consistent with what is observed in autopsy tissue isolated from echovirus infected 317 neonates, which also indicates extensive infection-induced hepatocyte damage d $^{23,35,38,39}$.

318 Consistent with high levels of infection in the liver, $\mathrm{hFcRn}{ }^{\text {Tg32 }}$-IFNAR ${ }^{-/-}$infected animals also 319 exhibited infectious virus present in the stool. Given that echoviruses are transmitted by the fecaloral route, defining how viral particles are shed and subsequently transmitted is important for understanding pathogenesis and spread. Because infected animals did not have high titers in the small intestine $\left(\sim 10^{2} \mathrm{PFU} / \mathrm{mg}\right.$ on average), our data indicate that shed virus does not result from direct intestinal infection, which is expected given the route of inoculation. The most likely scenario is via the gut-liver axis. Many studies have shown that the bacteria and bacterial products can reach the liver through the portal vein and liver secretory products, such as bile acids, IgA, and antimicrobial molecules, can leave the liver into the intestines through the biliary tract ${ }^{40,41}$. It is thus likely that infectious virus exits the liver through the biliary tract into the intestine where it exits the body in the stool, explaining the high stool titers with little to no infectious virus in the intestine itself.

There are currently no effective antiviral therapeutics to combat echovirus infections. Our work thus establishes in vivo models that full recapitulate echovirus infection in human neonates and could thus be used to develop and test antivirals. In addition, our studies define key roles for FcRn and type I IFN signaling in mediating echovirus pathogenesis and suggest these factors could be 334 targeted to ameliorate or prevent infections. Collectively, this work defines fundamental aspects 
335 of echovirus biology that enhance our understanding of how infection, tissue targeting, and 336 disease occurs.

\section{Materials and Methods}

340 Cell lines and viruses. HeLa cells (clone 7B) were provided by Jeffrey Bergelson, Children's 341 Hospital of Philadelphia, Philadelphia, PA, and cultured in MEM supplemented with 5\% FBS, non342 essential amino acids, and penicillin/streptomycin. Experiments were performed with echovirus 34311 Gregory (E11), which was obtained from the ATCC. Virus was propagated in HeLa cells and purified by ultracentrifugation over a $30 \%$ sucrose cushion, as described previously ${ }^{42}$.

Animals. All animal experiments were approved by the University of Pittsburgh Animal Care and Use Committee and all methods were performed in accordance with the relevant guidelines and regulations. C57BL/6J (WT, cat. no. 000664), B6.Cg-Fcgr ${ }^{\mathrm{tm} 1 \mathrm{Dcr} T g(F C G R T) 32 D c r / D c r J}$ (hFcRn ${ }^{\text {Tg32 }}$, cat. no. 014565), B6(Cg)-Ifnar1 ${ }^{\text {tm1.2Ees }} / J\left(\right.$ IFNAR $^{-/-}$, cat. no. 028288) were purchased from The Jackson Laboratory. hFcRn ${ }^{T g 32}$ IFNAR $^{-/-}$mice were generated by crossing B6.129S2Ifnar1 $^{\text {tm1Agt/Mmjax (cat no. 32045-JAX) with B6.Cg-Fcgrt }}{ }^{\text {tm1Dcr }}$ Tg(FCGRT)32Dcr/DcrJ (cat no. 014565). Breeders were established that were deficient in mouse FcRn and IFNAR and were homozygous for the hFcRn transgene. All animals used in this study were genotyped by

\section{Transnetyx.}

Adult animal infections. 6-7-week-old mice were inoculated by the intraperitoneal route with $10^{4}$ PFU of E11. Intraperitoneal inoculation was performed using a $1 \mathrm{~mL}$ disposable syringe and a 25gauge needle in $100 \mu \mathrm{L}$ of $1 \mathrm{X}$ PBS. Mice were euthanized at 3 days post inoculation, or at times specified in the figure legends, and organs harvested into $1 \mathrm{~mL}$ of DMEM (viral titration) or RNA lysis buffer (RNA isolation) and stored at $-80^{\circ} \mathrm{C}$. Tissue samples for viral titration were thawed 
and homogenized with a TissueLyser LT (Qiagen) for 8 minutes, followed by brief centrifugation

for 5 minutes at $5000 \times \mathrm{g}$. Viral titers in organ homogenates were determined by plaque assay in HeLa cells overlayed with a $1: 1$ mixture of $1 \%$ agarose and $2 x$ MEM (4\% FBS, $2 \%$ pen/strep, $2 \%$ NEAA). Plaques were enumerated 40hpi following crystal violet staining.

Suckling pup infections. 7 -day-old mice were inoculated by the intraperitoneal route with $10^{4}$ PFU of E11. Two separate litters were inoculated for each condition. Intraperitoneal inoculation was performed using a $1 \mathrm{~mL}$ disposable syringe and a 27 -gauge needle in $50 \mu \mathrm{L}$ of $1 \mathrm{X}$ PBS. Mice were euthanized at 3 days post inoculation and organs harvested into $0.5 \mathrm{~mL}$ of DMEM (viral titration) or RNA lysis buffer (RNA isolation) and stored at $-80^{\circ} \mathrm{C}$. Tissue samples for viral titration were thawed and homogenized with a TissueLyser LT (Qiagen) for 5 minutes, followed by brief centrifugation for 5 minutes at $8000 \times \mathrm{g}$. Viral titers in organ homogenates were determined by TCID50 in HeLa cells and enumerated following crystal violet staining.

Immunohistochemistry. Tissues were fixed in $10 \%$ buffered formalin for $24 \mathrm{hrs}$ and then transferred to $70 \%$ ethanol. Tissues were embedded in paraffin and sectioned. Slides were stained with a monoclonal VP1 antibody, as described previously ${ }^{9}$, or cleaved caspase 3 . Tissue sections were deparaffinized with xylene and rehydrated with decreasing concentrations of 379 ethanol $(100 \%, 95 \%, 80 \%)$, then washed with $\mathrm{ddH}_{2} \mathrm{O}$. Antigen unmasking was performed with slides submerged in $10 \mathrm{mM}$ citrate buffer $(\mathrm{pH} \mathrm{6.0)}$ and heated in a steamer for 20 minutes at $381 \sim 90^{\circ} \mathrm{C}$. Slides were cooled to room temperature and slides were immunostained with cleaved caspase 3 using Vectastain Elite ABC HRP (Vector Biolabs, PK-6100), according to the manufacturer's instructions. Slides were incubated in $6 \% \mathrm{H}_{2} \mathrm{O}_{2}$ in methanol for 30 min then washed 3 times for 5 minutes in $\mathrm{H}_{2} \mathrm{O}$. Avidin block (Vector, SP-2001) was applied for 15 minutes and washed twice in $\mathrm{H}_{2} \mathrm{O}$ followed by biotin block (Abcam, ab156024) for 15 minutes and washed 
twice in $\mathrm{H}_{2} \mathrm{O}$. Finally, serum-free protein block was applied for 10 minutes and cleaved caspase 3 antibody was diluted 1:100 in TBS-T (Tris-buffered saline, $0.1 \%$ Tween 20 ) and slides incubated overnight in a humidified chamber at 4C. Next, slides were washed three times for 5 min in PBST and exposed to the goat anti-rabbit biotinylated secondary antibody (Vector, BA-1000) for 30 min. Slides were rinsed in PBST three times for $5 \mathrm{~min}$ and the Vectastain Elite ABC HRP kit was applied for $30 \mathrm{~min}$. Slides were rinsed in PBST for three times for $5 \mathrm{~min}$ and diaminobenzidine substrate for 5 mins; which was terminated with water incubation. Slides were counterstained with hematoxylin for $1 \mathrm{~min}$, thoroughly rinsed with $\mathrm{H}_{2} \mathrm{O}$, and incubated in $0.1 \%$ sodium bicarbonate in $\mathrm{H} 2 \mathrm{O}$ for 5 mins. Slides were then dehydrated with increasing concentrations of ethanol, cleared with xylene and mounted with Cytoseal 60 (Thermo Scientific, 83104). Images were captured on an IX83 inverted microscope (Olympus) using a UC90 color CCD camera (Olympus).

Antibodies. The following antibodies were used- anti-VP1 (NCL-ENTERO, clone 5-D8/1, Leica Biosystems) and cleaved caspase 3 (Asp175) (9661, Cell Signaling).

HCR and Imaging. HCR was performed following the Molecular Instruments HCR v3.0 protocol for FFPE human tissue sections ${ }^{25,27}$. Briefly, tissue sections were deparaffinized with xylene and rehydrated with decreasing concentrations of ethanol (100\%, 95\%, $80 \%)$. Antigen unmasking was performed with slides submerged in $10 \mathrm{mM}$ citrate buffer $(\mathrm{pH} \mathrm{6.0)}$ and heated in a steamer for 20 minutes at $\sim 90^{\circ} \mathrm{C}$. Slides were cooled to room temperature. Sections were treated with $10 \mu \mathrm{g} / \mathrm{mL}$ Proteinase $\mathrm{K}$ for $10 \mathrm{~min}$ at $37^{\circ} \mathrm{C}$ and washed with RNase free water. Samples were incubated for 40710 minutes at $37^{\circ} \mathrm{C}$ in hybridization buffer. Sections were incubated overnight in a humidified 408 chamber at $37^{\circ} \mathrm{C}$ with 0.4 pmol of initiator probes in hybridization buffer (Table 1 echovirus probes, 409 Table 2 albumin probes). The next day, slides were washed in probe wash buffer and 5x SSCT 410 for $4 \times 15 \mathrm{~min}$, according to the manufacturer's instructions. Samples were incubated in a 
411 humidified chamber at $37^{\circ} \mathrm{C}$ for 30 minutes in amplification buffer. Fluorescent hair pins were

412 heated to $95^{\circ} \mathrm{C}$ for 90 seconds and snap cooled at room temperature for $30 \mathrm{~min}$. Hairpins and

413 amplification buffer were added to the sample and incubated overnight at room temperature.

414 Hairpins were washed off with $5 x$ SSCT for 5 minutes, 15 minutes, 15 minutes, and 5 minutes.

415 Slides were mounted in vectashield with DAPI. Slides were imaged an IX83 inverted microscope

416 (Olympus) with ORCA-FLASH 4.0 camera. Olympus CellSens advanced imaging software with

417 the deconvolution package, constrained iterative, was used.

RNA extraction and RNAseq. Total RNA was prepared using the Sigma GenElute total mammalian RNA miniprep kit with optional DNase step, according to the protocol of the manufacturer. RNA quality was assessed by Nanodrop and an Agilent RNA Screen Tape System, and 1ug was used for library preparation using RNA with Poly A selection kit (Illumina), as per the

423 manufacturer's instructions. Sequencing was performed on an Illumina HiSeq. RNA-sea FASTQ 424 data were processed and mapped to the mouse reference genome (GRCm38) using CLC 425 Genomics Workbench 20 (Qiagen). Differential gene expression was performed using the 426 DESeq2 package in $\mathrm{R}^{43}$. Heatmaps were made in $\mathrm{R}$ using the pheatmap: pretty heatmaps 427 package shown as the $\log _{2}$ RPKM. Raw sequencing files have been deposited in Sequence Read 428 Archives (SUB8204864, PRJNA665496).

430 Luminex assays. Luminex profiling was performed on whole blood that was allowed to clot for 43120 minutes and then spun down using a custom mouse IFN kit (IFN alpha, IFN beta, IL-28, 432 Invitrogen), mouse cytokine 23-plex (Bio-Rad, M60009RDPD), and mouse chemokine 31-plex 433 (Bio-Rad, 12009159), according to the manufacturer's protocol. Assays were read on a Millipore 434 MagPix machine by the Luminex Corporation. Heat maps were generated using the fold change 435 in concentration (picograms/milliliter) of each animal compared to the average of uninfected 
436 animals and was made in GraphPad Prism. Violin plots are shown as the concentration for each

437 animal (one point) in picograms/milliliter.

\section{8}

439 Statistics. All statistical analysis was performed using GraphPad Prism version 8. Data are

440 presented as mean \pm SD. A one-way ANOVA was used to determine statistical significance, as

441 described in the figure legends. Parametric tests were applied when data were distributed

442 normally based on D'Agostino-Pearson analyses; otherwise nonparametric tests were applied. P

443 values of $<0.05$ were considered statistically significant, with specific $P$ values noted in the figure 444 legends. 
446

\section{Literature cited}

1. Khetsuriani, N., Lamonte-Fowlkes, A., Oberst, S. \& Pallansch, M. A. Enterovirus surveillance--United States, 1970-2005. MMWR. Surveill. Summ. Morb. Mortal. Wkly. report. Surveill. Summ. / CDC (2006).

2. Morens, D. M. Enteroviral disease in early infancy. J. Pediatr. (1978). doi:10.1016/S00223476(78)80422-3

3. Civardi, E. et al. Viral outbreaks in neonatal intensive care units: What we do not know. Am. J. Infect. Control 41, 854-856 (2013).

4. Naing, Z. et al. Prevalence of viruses in stool of premature neonates at a neonatal intensive care unit. J. Paediatr. Child Health 49, (2013).

5. Verboon-Maciolek, M. A., Krediet, T. G., Gerards, L. J., Fleer, A. \& Van Loon, T. M. Clinical and epidemiologic characteristics of viral infections in a neonatal intensive care unit during a 12-year period. Pediatr. Infect. Dis. J. 24, 901-904 (2005).

6. Isaacs, D. et al. Conservative Management of an Echovirus 11 Outbreak in a Neonatal Unit. Lancet 333, 543-545 (1989).

7. Civardi, E. et al. Viral outbreaks in neonatal intensive care units: What we do not know. Am. J. Infect. Control 41, 854-856 (2013).

8. Ho, S. Y. et al. Investigation and successful control of an echovirus 11 outbreak in neonatal intensive care units. Pediatr. Neonatol. 61, 180-187 (2019).

9. Morosky, S. et al. The neonatal Fc receptor is a pan-echovirus receptor. Proc. Natl. Acad. Sci. 116, 3758-3763 (2019).

10. Zhao, X. et al. Human Neonatal Fc Receptor Is the Cellular Uncoating Receptor for Enterovirus B. Cell 177, 1-13 (2019).

11. Dickinson, B. L. et al. Bidirectional FcRn-dependent IgG transport in a polarized human intestinal epithelial cell line. J. Clin. Invest. 104, 903-911 (1999).

12. Chaudhury, C. et al. The Major Histocompatibility Complex-related Fc Receptor for IgG (FcRn) Binds Albumin and Prolongs Its Lifespan. J. Exp. Med. 197, 315-322 (2003).

13. Cianga, C., Cianga, P., Plamadeala, P. \& Amalinei, C. Nonclassical major histocompatibility complex l-like Fc neonatal receptor ( $F c R n)$ expression in neonatal human tissues. Hum. Immunol. 72, 1176-1187 (2011).

14. Ren, R., Costantini, F., Gorgacz, E. J., Lee, J. J. \& Racaniello, V. R. Transgenic mice expressing a human poliovirus receptor: A new model for poliomyelitis. Cell 63, 353-362 (1990).

15. Fujii, K. et al. Transgenic mouse model for the study of enterovirus 71 neuropathogenesis. doi:10.1073/pnas. 1217563110

16. Wang, Y. \& Pfeiffer, J. K. Emergence of a large-plaque variant in mice infected with coxsackievirus B3. MBio 7, 1-10 (2016).

17. Khan, S. et al. Poliomyelitis in transgenic mice expressing CD155 under the control of the Tage4 promoter after oral and parenteral poliovirus inoculation. J. Gen. Virol. 95, 16681676 (2014).

18. Ohka, S. et al. Establishment of a Poliovirus Oral Infection System in Human Poliovirus Receptor-Expressing Transgenic Mice That Are Deficient in Alpha/Beta Interferon Receptor. J. Virol. 81, 7902-7912 (2007).

19. Koestner, W. et al. Interferon-beta expression and type I interferon receptor signaling of 
hepatocytes prevent hepatic necrosis and virus dissemination in Coxsackievirus B3infected mice. PLoS Pathog. 14, 1-23 (2018).

20. Bergelson, J. M. et al. Identification of the Integrin VLA-2 as a Receptor for Echovirus 1. Science (80-. ). 255, 1718-1720 (1992).

21. Hughes, S. A., Thaker, H. M. \& Racaniello, V. R. Transgenic mouse model for echovirus myocarditis and paralysis. Proc. Natl. Acad. Sci. U. S. A. 100, 15906-15911 (2003).

22. Garcia, A. G., Basso, N. G., Fonseca, M. E. \& Outani, H. N. Congenital echo virus infection--morphological and virological study of fetal and placental tissue. J. Pathol. 160, 123-7 (1990).

23. Wang, J., Atchison, R. W., Walpusk, J. \& Jaffe, R. Echovirus hepatic failure in infancy: report of four cases with speculation on the pathogenesis. Pediatr. Dev. Pathol. 4, 45460 (2001).

24. Good, C., Wells, A. I. \& Coyne, C. B. Type III interferon signaling restricts Enterovirus 71 infection of goblet cells. Sci. Adv. 5, 1-11 (2019).

25. Choi, H. M. T. et al. Third-generation in situ hybridization chain reaction: Multiplexed, quantitative, sensitive, versatile, robust. Dev. 145, 1-10 (2018).

26. Dirks, R. M. \& Pierce, N. A. Triggered amplification by hybridization chain reaction. Proc. Natl. Acad. Sci. U. S. A. 101, 15275-15278 (2004).

27. Choi, H. M. T. et al. Mapping a multiplexed zoo of mRNA expression. Dev. 143, 36323637 (2016).

28. Shah, U. et al. Distribution of the IgG Fc receptor, FcRn, in the human fetal intestine. Pediatr. Res. 53, 295-301 (2003).

29. Israel, E. J. et al. Expression of the neonatal Fc receptor, FcRn, on human intestinal epithelial cells. Immunology 92, 69-74 (1997).

30. Pyzik, M. et al. Hepatic FcRn regulates albumin homeostasis and susceptibility to liver injury. Proc. Natl. Acad. Sci. 114, E2862-E2871 (2017).

31. Blumberg, R. S. et al. A major histocompatibility complex class I- related Fc receptor for IgG on rat hepatocytes. J Clin Invest. Clin. Invest 95, 2397-2402 (1995).

32. Bersani, I. et al. Neonatal acute liver failure due to enteroviruses: a 14 years single NICU experience. J. Matern. Neonatal Med. (2020). doi:10.1080/14767058.2018.1555806

33. Morgan, C., Thomson, S. J., Legg, J. \& Narat, S. A Case of Fulminant Hepatitis due to Echovirus 9 in a Patient on Maintenance Rituximab Therapy for Follicular Lymphoma. Case Rep. Hematol. 2015, 1-4 (2015).

34. Lefterova, M. I., Rivetta, C., George, T. I. \& Pinsky, B. A. Severe hepatitis associated with an echovirus 18 infection in an immune-compromised adult. J. Clin. Microbiol. 51, 684687 (2013).

35. Bajema, K. L. et al. Acute Liver Failure Due to Echovirus 9 Associated With Persistent BCell Depletion From Rituximab. Open Forum Infect. Dis. 4, 9-11 (2017). 
infection: Autopsy case report and review of the literature. Mod. Pathol. (2001).

39. Pedrosa, C., Lage, M. J. \& Virella, D. Congenital echovirus 21 infection causing fulminant

40. Tripathi, A. et al. The gut-liver axis and the intersection with the microbiome. Nat. Rev.

41. Ohtani, N. \& Kawada, N. Role of the Gut-Liver Axis in Liver Inflammation, Fibrosis, and Cancer: A Special Focus on the Gut Microbiota Relationship. Hepatol. Commun. 3, 456470 (2019).

42. Morosky, S., Lennemann, N. J. \& Coyne, C. B. BPIFB6 Regulates Secretory Pathway

43. Love, M. I., Huber, W. \& Anders, S. Moderated estimation of fold change and dispersion for RNA-seq data with DESeq2. Genome Biol. 15, 1-21 (2014).

\section{Acknowledgements}

549 We thank Charles Good (UPMC Children's Hospital of Pittsburgh) and Kathryn Lemon (UPMC

550 Cancer Center) for technical assistance, Jeffrey Bergelson (Children's Hospital of Philadelphia)

551 for reagents, Runjan Chetty (Brighton and Sussex University Hospitals NHS Trust) for blinded

552 pathology analysis, and Terence Dermody (UPMC Children's Hospital of Pittsburgh) for helpful

553 suggestions. This project was supported by NIH R01-Al150151 (C.B.C), NIH R01-AI081759

554 (C.B.C.), NIH T32-AI060525 (A.I.W), NIH F31-Al149866 (A.I.W), a Burroughs Wellcome

555 Investigators in the Pathogenesis of Infectious Disease Award (C.B.C), and the UPMC Children's

556 Hospital of Pittsburgh (C.B.C). This project also used the UPMC Hillman Cancer Center Tissue

557 and Research Pathology/Pitt Biospecimen Core and Animal Facility shared resources which are 


\section{Figure 1}
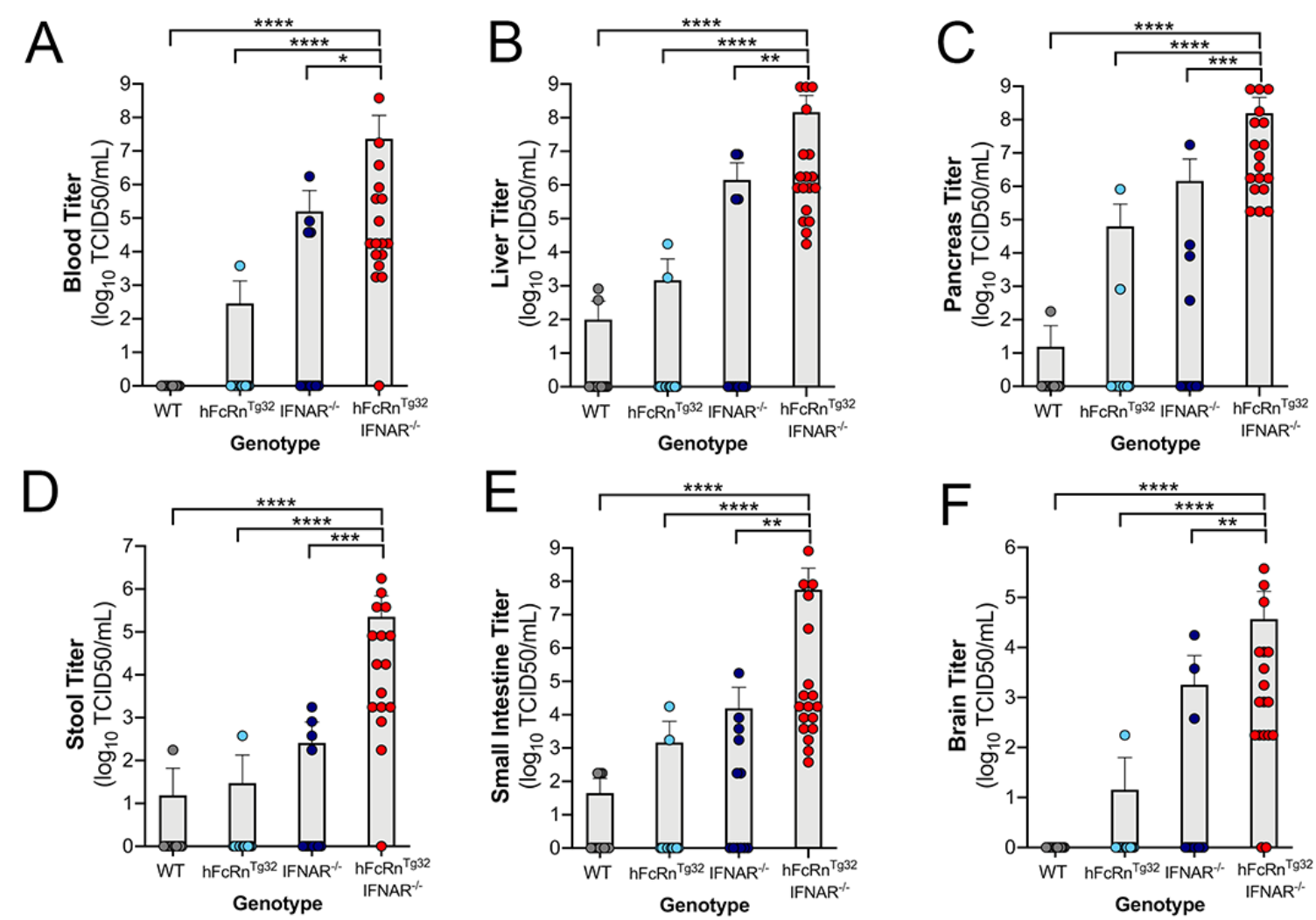

560

561

562

563

564

565

566

567

568

569
Figure 1. $h F c n^{T g 32}$-IFNAR ${ }^{-/-}$suckling mice are permissive to E11 infection. C57BI/6 (WT, gray), hFcRn ${ }^{T g 32}$ (light blue), IFNAR ${ }^{-/-}$(dark blue), or hFcRn ${ }^{\text {Tg32 }}$-IFNAR ${ }^{-/}$(red) suckling mice were IP inoculated with $10^{4}$ PFU of E11 and sacrificed 72 hours post inoculation. Viral titers $\left(\log _{10} \mathrm{TCID} 50 / \mathrm{mL}\right)$ of suckling mice $\left(\mathrm{WT}-12, \mathrm{hFcRn}{ }^{\mathrm{Tg} 32}-13, \mathrm{IFNAR}^{-/-}-12, \mathrm{hFcRn}^{\mathrm{Tg} 32}\right.$ IFNAR $^{-/-}$ -18 animals) in the blood (A), liver (B), pancreas (C), stool (D), small intestine (E), and brain (F) are shown as mean \pm standard deviation and individual animals (points). Data are shown with significance determined with a Kruskal-Wallis test with a Dunn's test for multiple comparisons $\left({ }^{*} p<0.05,{ }^{* *} p<0.005,{ }^{* * *} p<0.0005,{ }^{* * *} p<0.0001\right)$. 
Figure 2
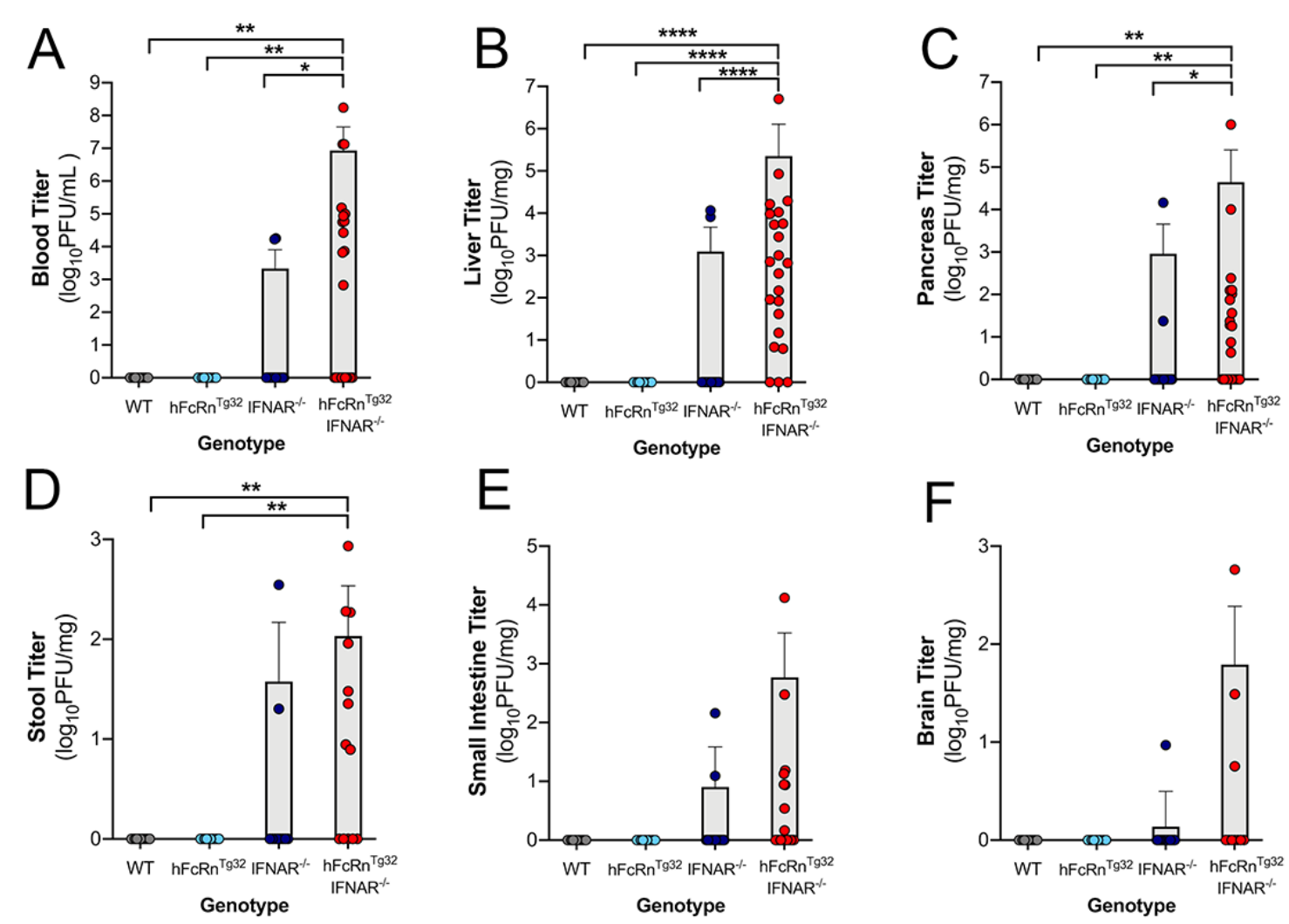

571
Figure 2. $\mathrm{hFcRn}^{\text {Tg32 }}$-IFNAR ${ }^{-/-}$adult mice are permissive to E11 infection. C57/BL6 (WT, gray), $\mathrm{hFcRn}^{\mathrm{Tg} 32}$ (light blue), IFNAR ${ }^{-/-}$(dark blue), and $\mathrm{hFCRn}^{\mathrm{Tg} 32}$-IFNAR ${ }^{-/-}$(red) animals were IP inoculated with $10^{4}$ PFU of E11 and sacrificed 72 hours post inoculation. (A) Viral titers in the blood $\left(\log _{10} \mathrm{PFU} / \mathrm{mL}\right)$ of adult animals (WT $-11, \mathrm{hFCRn}^{\text {Tg32 }}-10$, IFNAR ${ }^{-1-}-16, \mathrm{hFcRn}^{\text {Tg32 }}$-IFNAR $^{-}$ ${ }^{\prime-}-23$ animals). Viral titers in the liver $(B)$, pancreas $(C)$, stool $(D)$, small intestine $(E)$, and brain (F) $\left(\log _{10} \mathrm{PFU} / \mathrm{mg}\right)$ from adult mice are shown as mean \pm standard deviation bars and individual animals (points). Data are shown with significance determined with a Kruskal-Wallis test with a Dunn's test for multiple comparisons $\left({ }^{*} p<0.05,{ }^{* *} p<0.005,{ }^{* * *} p<0.0005,{ }^{* * * *} p<0.0001\right)$. 
Figure 3
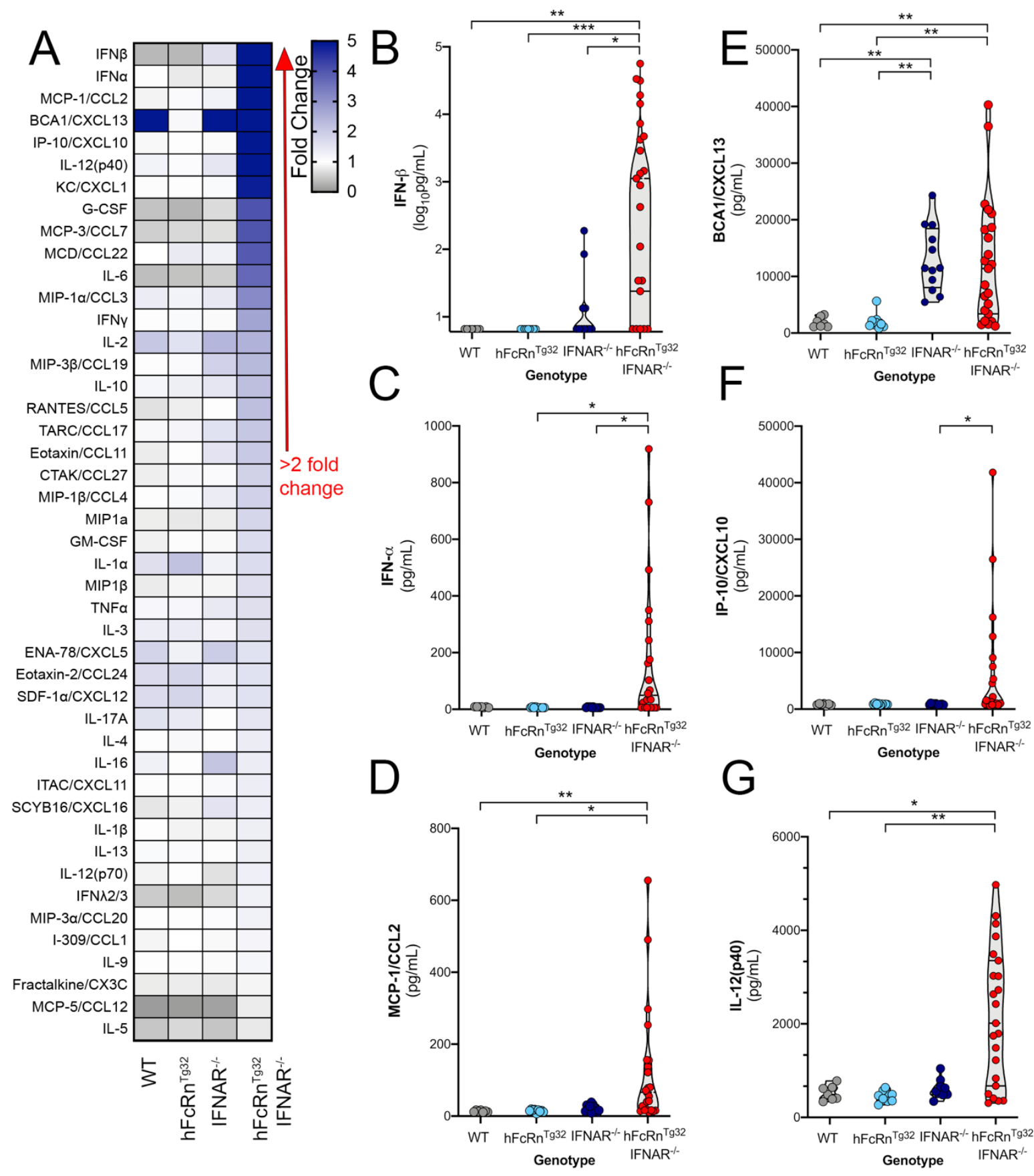

Figure 3. $\mathrm{hFcRn}{ }^{\mathrm{Tg} 32}$-IFNAR ${ }^{-/-}$animals induce a robust immune response to $\mathrm{E} 11$ infection. C57/BL6 (WT, gray), hFcRn ${ }^{\text {Tg32 }}$ (light blue), IFNAR ${ }^{-1-}$ (dark blue), and $\mathrm{hFcRn}^{\text {Tg32 }}$-IFNAR $^{-1-}$ (red) animals were IP inoculated with $10^{4}$ PFU of E11 and sacrificed 72 hours post inoculation. Luminex-based multianalyte profiling of 45 cytokines was then performed from whole blood. (A) Heatmap demonstrating the induction (shown as fold-change from uninfected control) in E11infected mice of the indicated genotype. Blue denotes significantly increased cytokines in comparison to untreated. Grey or white denote little to no changes (scale at top right). The red 
591 separate experiments. Luminex assays were performed in duplicate. (B-G) IFN- $\beta$ (B), IFN- $\alpha$ (C), 592 MCL-1/CCL2 (D), BCA1/CXCL13 (E), IP-10/CXCL10, and IL12(p40) cytokine levels in the blood of E11 infected C57BI/6 (WT, gray), hFcRn ${ }^{T g 32}$ (light blue), IFNAR ${ }^{-/-}$(dark blue), and hFcRn ${ }^{T g 32}$ IFNAR $^{-/-}$(red) animals. Symbols represent individual mice. Significance was determined with a Kruskal-Wallis test with a Dunn's test for multiple comparisons $\left({ }^{*} p<0.05,{ }^{* *} p<0.005,{ }^{* * *} p<0.0005\right)$. 
Figure 4.
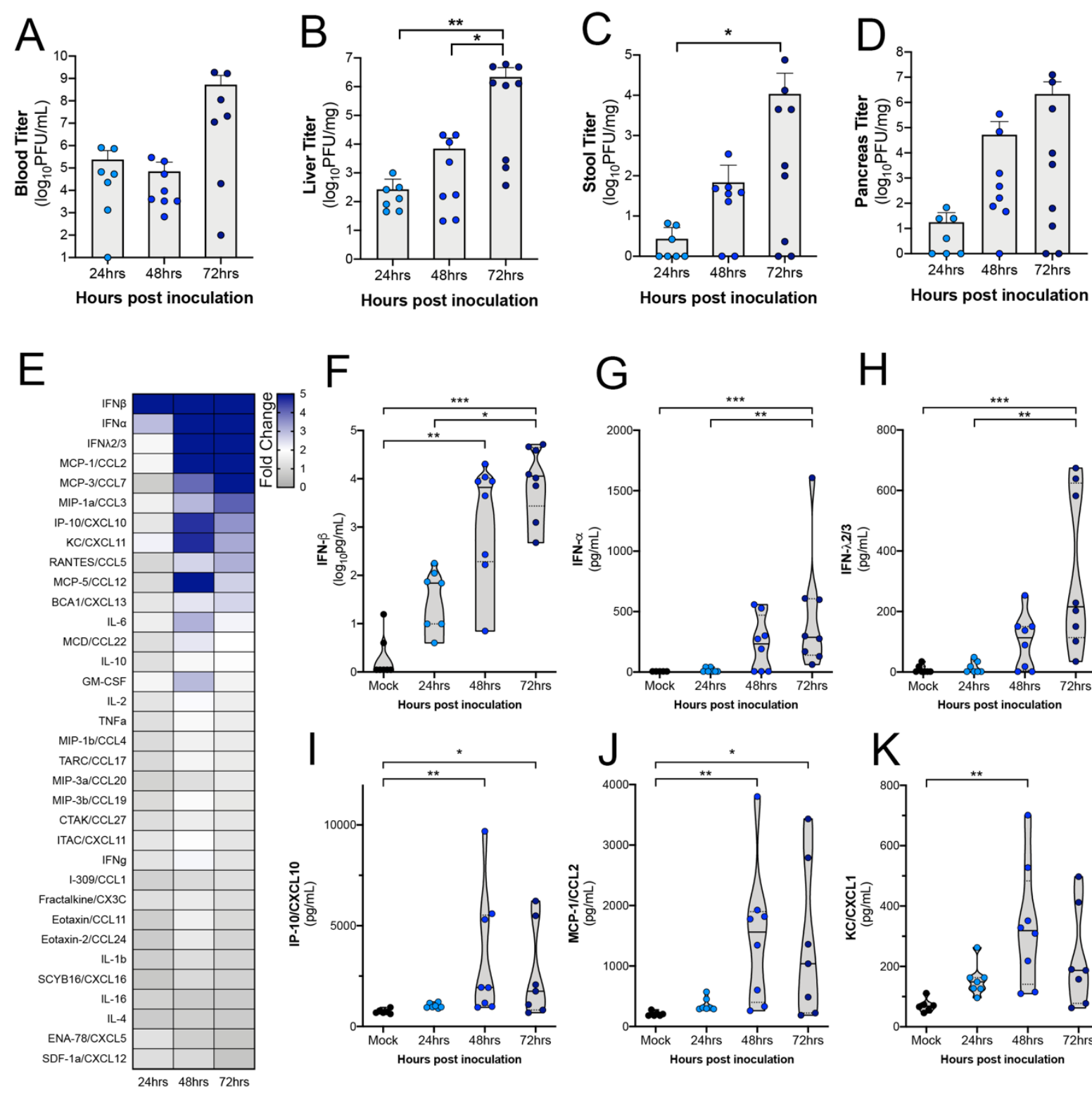

$\mathrm{H}$

Figure 4. Cytokine levels increase with viremia in $h F c n^{T g 32}-$ IFNAR $^{-/-}$animals. $h F c R n^{T g 32}$ IFNAR $^{-/-}$animals IP inoculated with $10^{4}$ PFU of E11 were sacrificed at 24 (light blue) 48 (blue), or 72 (navy) hours post inoculation. (A) Viral titers in the blood $\left(\log _{10} P F U / m L\right)$ of adult animals $(24 \mathrm{hpi}$ $-7,48 \mathrm{hpi}-8,72 \mathrm{hpi}-9$ animals) are shown as mean \pm standard deviation bars) and individual animals (points). (B-D) Viral titers in the liver (B), stool (C), and pancreas (D), ( $\left.\log _{10} \mathrm{PFU} / \mathrm{mg}\right)$ from adult mice are shown as mean \pm standard deviation bars and individual animals (points). (E) Heat map demonstrating the level of protein induction by Luminex-based assays shown as the fold change of from the average $\mathrm{pg} / \mathrm{mL}$ of the uninfected animals to each individual animal concentration per protein then averaged within each timepoint. Proteins are sorted from largest fold change (blue) from uninfected to smallest fold change (gray) in $72 \mathrm{hpi}$ animals. (F-K) IFN- $\beta$ (F), IFN- $\alpha(\mathrm{G}), \mathrm{IFN} \lambda 2 / 3(\mathrm{H}), \mathrm{IP}-10 / \mathrm{CXCL} 10(\mathrm{I}), \mathrm{MCP}-1 / \mathrm{CCL} 2(\mathrm{~J})$, and KC/CXCL1 (K) protein levels expressed in the blood of each animal shown by timepoint. Data are shown with significance 
bioRxiv preprint doi: https://doi.org/10.1101/2020.09.24.312058; this version posted September 24, 2020. The copyright holder for this preprint (which was not certified by peer review) is the author/funder. All rights reserved. No reuse allowed without permission.

610 determined with a Kruskal-Wallis test with a Dunn's test for multiple comparisons $\left({ }^{*} p<0.05\right.$, $\left.611{ }^{* *} p<0.005,{ }^{* * *} p<0.0005,{ }^{* * * *} p<0.0001\right)$.

612

613

614 
Figure 5.
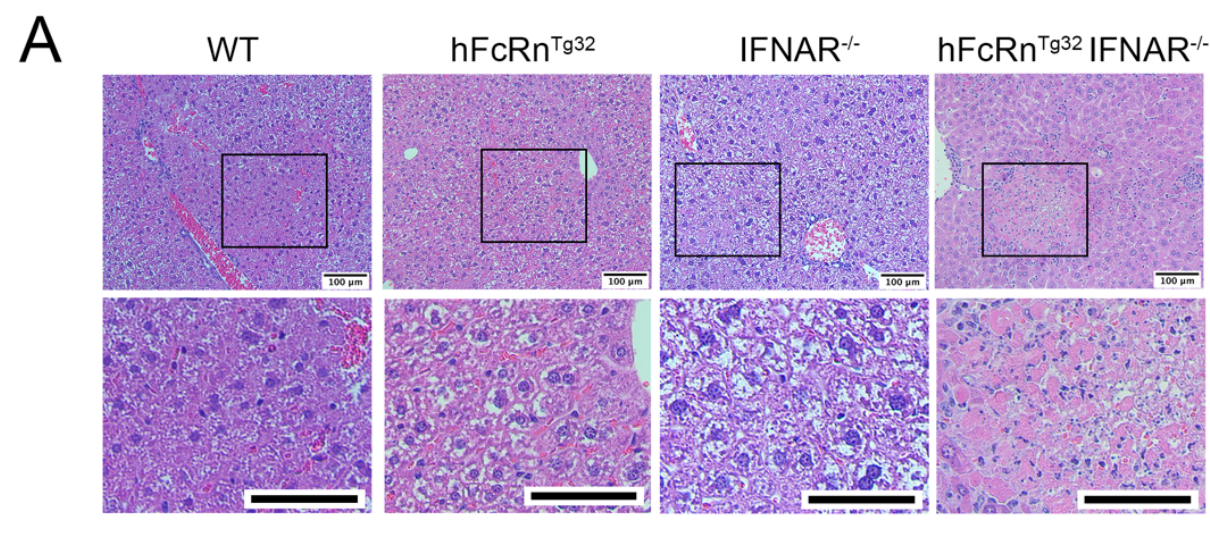

B
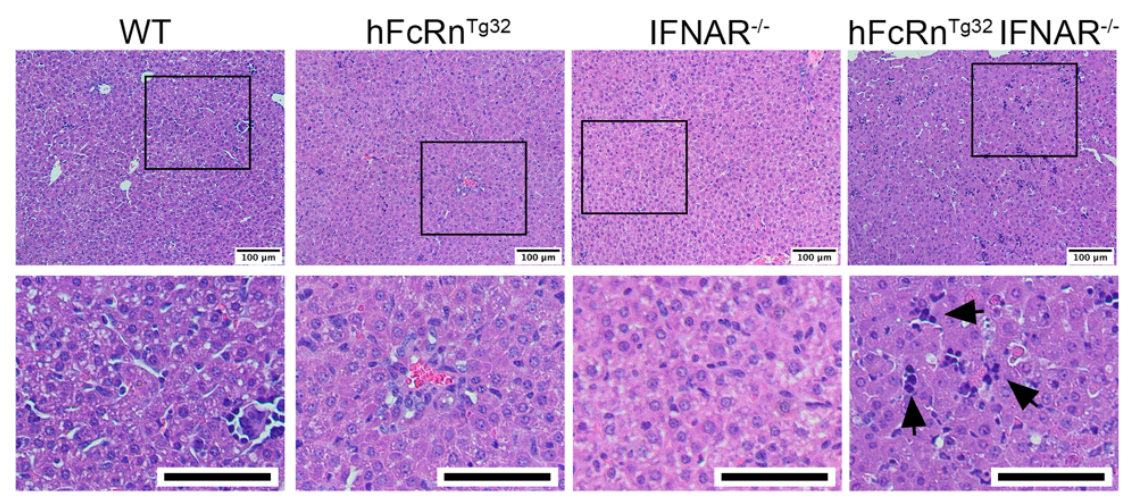

C

WT

$\mathrm{hFCRn}^{\mathrm{Tg} 32}$

IFNAR ${ }^{-/-}$

$\mathrm{hFCRn}^{\mathrm{Tg} 32}$ IFNAR $^{-/-}$

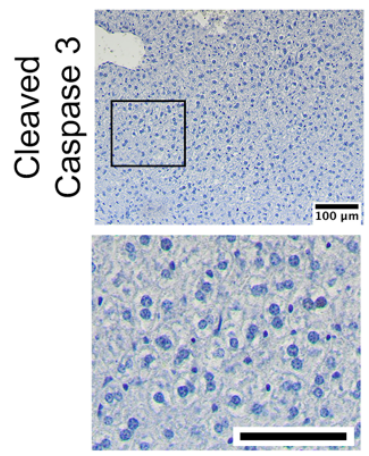

D
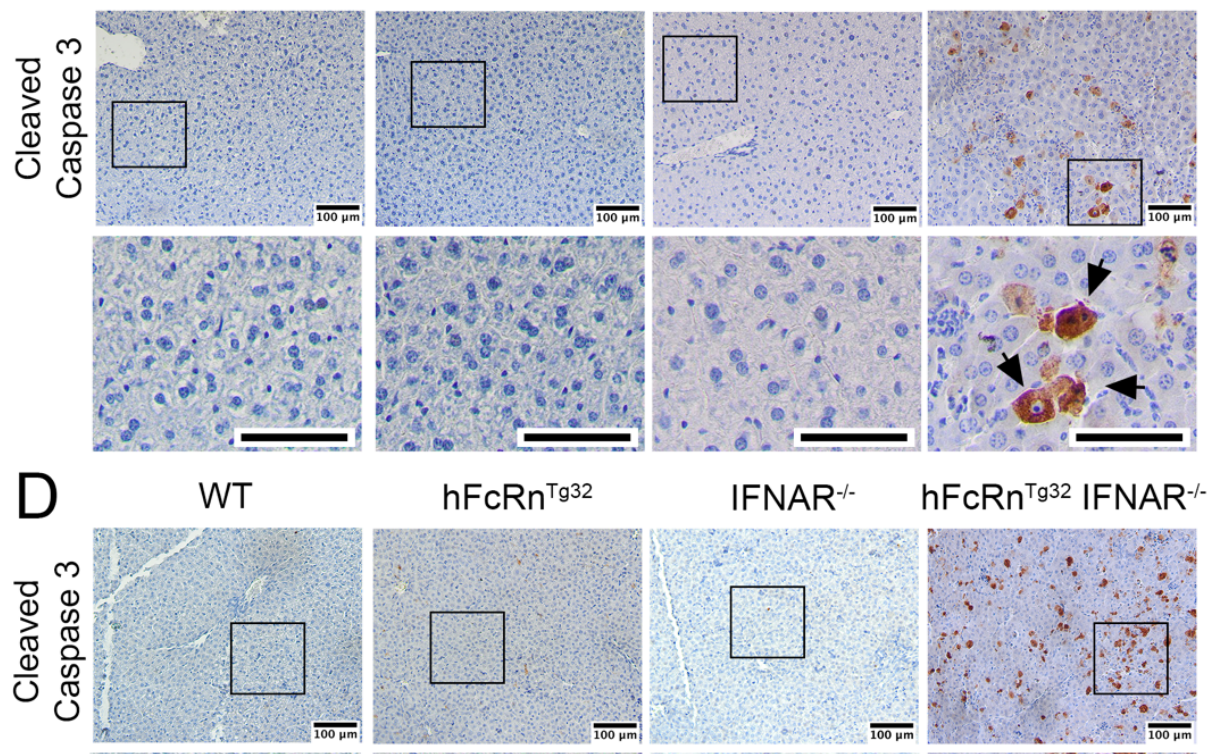

$\mathrm{hFcRn}{ }^{\top 932}$

IFNAR ${ }^{-/-}$

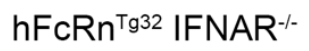


bioRxiv preprint doi: https://doi.org/10.1101/2020.09.24.312058; this version posted September 24, 2020. The copyright holder for this preprint (which was not certified by peer review) is the author/funder. All rights reserved. No reuse allowed without permission.

619 inoculated with $10^{4}$ E11 and sacrificed 72 hours post inoculation. (A \& B) H\&E staining of the 620 livers in adult (A) or suckling (B) mice. (C \& D) Immunohistochemistry using an antibody 621 recognizing the cleaved form of caspase 3 from the livers of a representative animal of each 622 genotype as indicated. Adult (C) and suckling mice (D). Black arrows denote positive staining. 623 Scale bars $(100 \mu \mathrm{m})$ are shown at bottom right. 
Figure 6
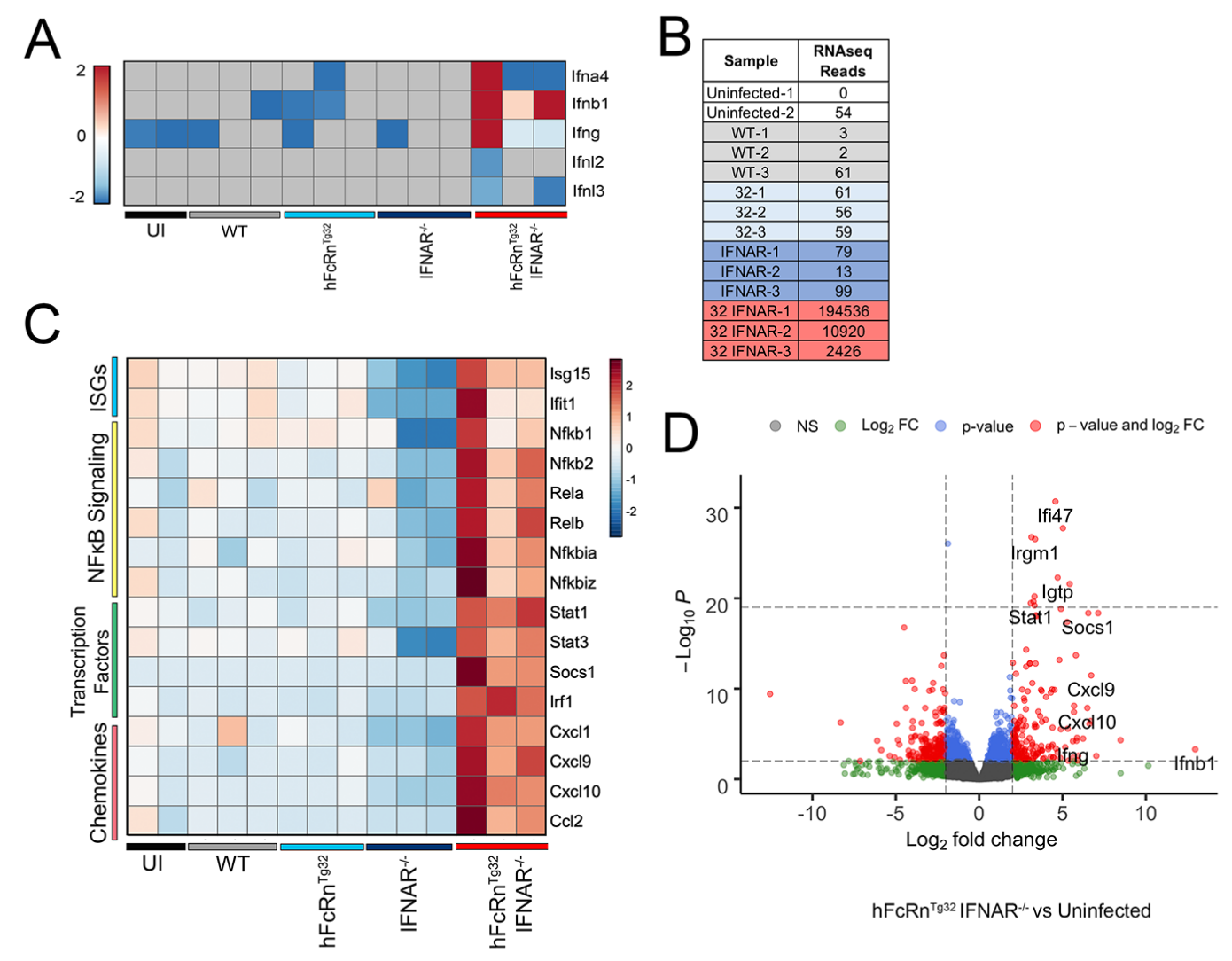

$h F c n^{T 932}$ IFNAR $^{-/ v}$ vs Uninfected

627

Figure 6. Transcriptional profiling from the livers of $E 11$ infected $h F c R n^{T g 32}{ }^{-I F N A R^{-/-}}$ animals reveals induction of a proinflammatory immune response to infection. RNAseqbased transcriptional profiling from RNA isolated from the livers of E11 infected C57BI/6 (WT), $\mathrm{hFcRn}^{\mathrm{Tg} 32}$, IFNAR ${ }^{-/-}$or hFcRn ${ }^{\mathrm{Tg} 32}$-IFNAR ${ }^{-1-}$ animals (3 animals each), or uninfected controls (2 animals) was performed. (A) Heatmap of $\log _{2} R P K M$ values for type I (Ifna4, Ifnb1), II (Ifng), and III (Ifnl2, Ifnl3) IFNs in the livers of the indicated genotypes $72 \mathrm{hpi}$. Scale shown at left. (B) RPKM values mapped to the E11 genomic sequence in each genotype. Individual animals are shown. (C) Heatmap based on $\log _{2}$ RPKM values of select proinflammatory cytokines in the livers of following E11 infection of the indicated genotypes, or uninfected controls. Scale is shown at right. In $(A)$ and $(C)$, red indicates higher expression and blue indicates lower expression. Grey denotes no reads detected. (D) Volcano plot of differentially regulated genes in $\mathrm{hFcRn}{ }^{\mathrm{Tg} 32}{ }_{\text {-IFNAR }} \mathrm{FN}^{-1-}$ adult animals compared to uninfected animals. Red indicates genes with a statistically significant upregulation or downregulation of $>$ or $<\log _{2}$ fold-change of 2 and $p<0.05$. 
A

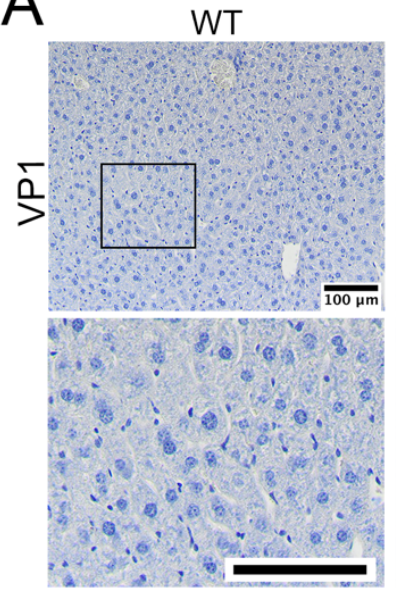

B
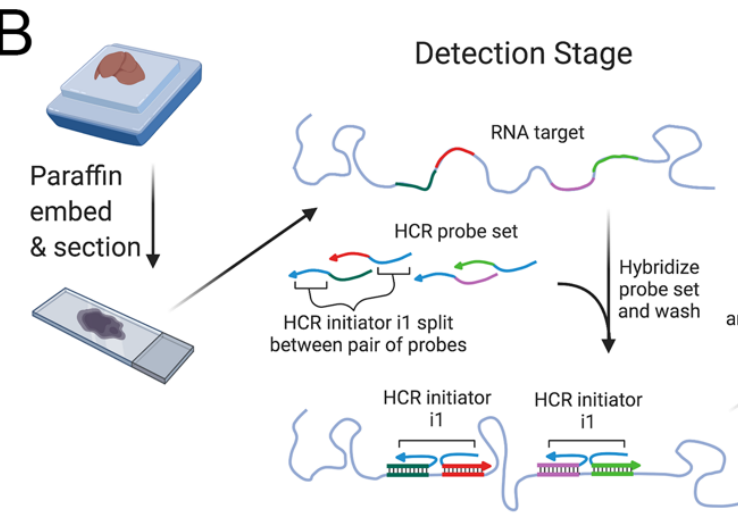

C
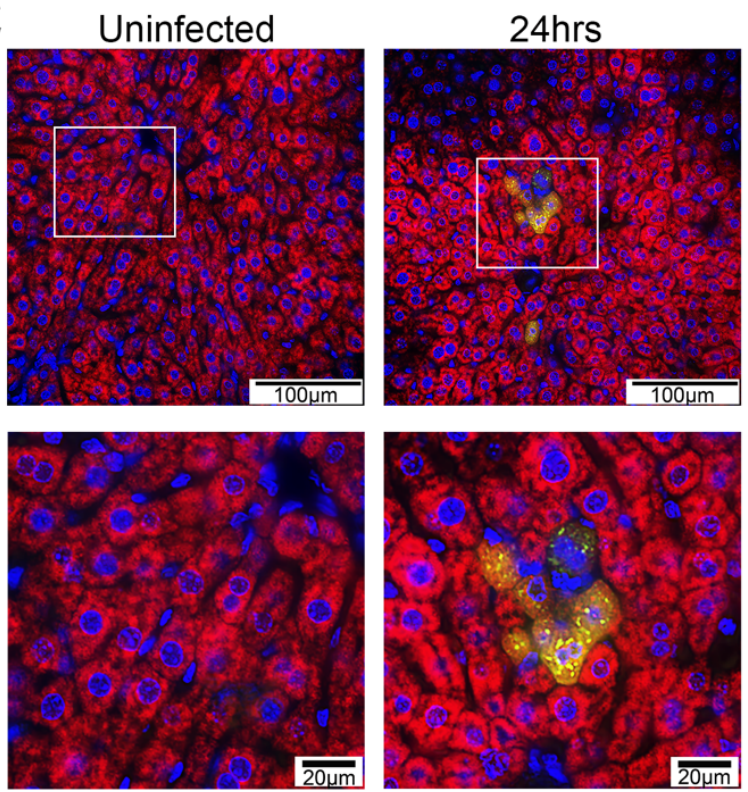

IFNAR ${ }^{-/-}$

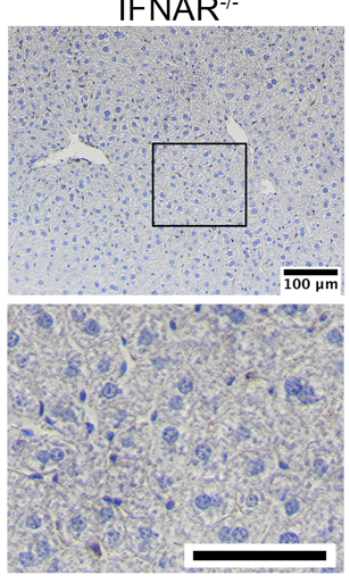

$\mathrm{hFCRn}^{\mathrm{Tg} 32}$ IFNAR ${ }^{-/-}$

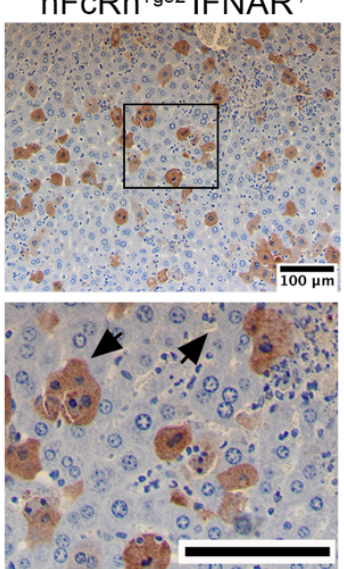

Amplification Stage
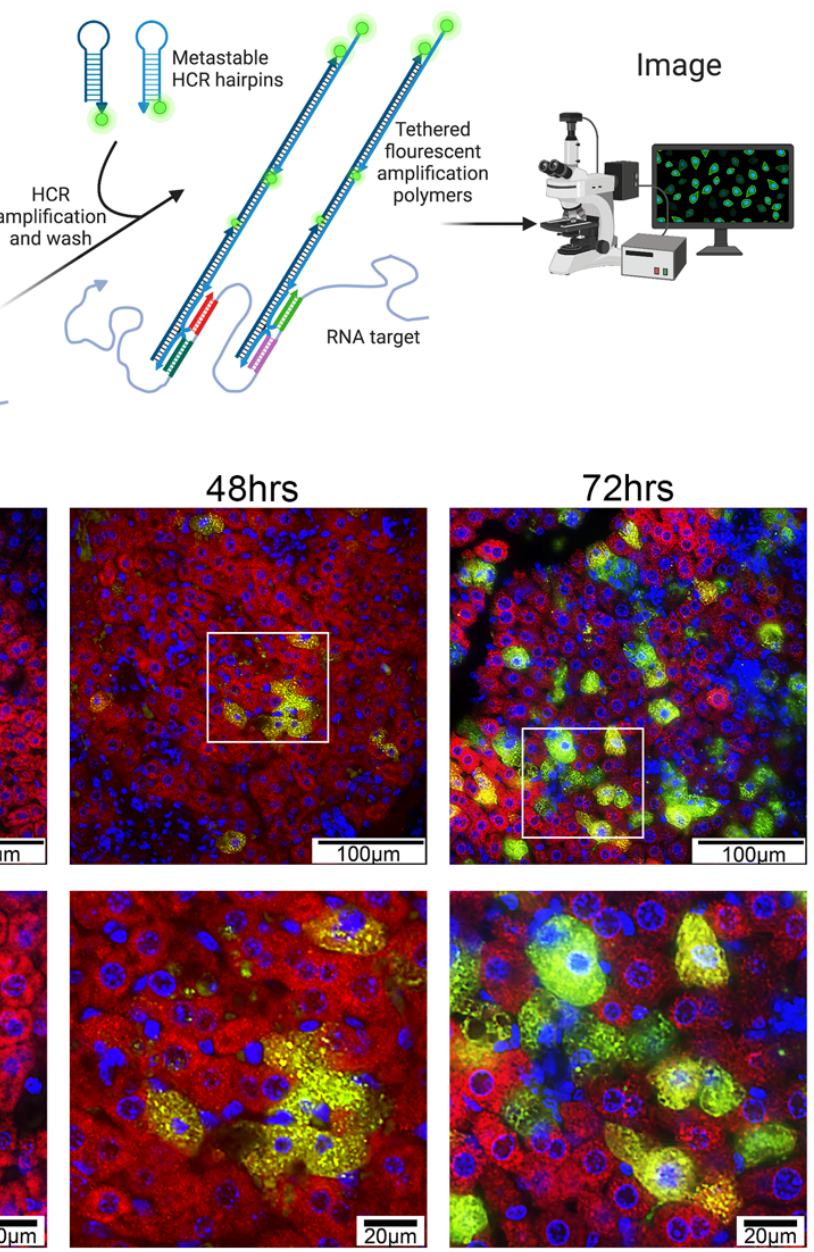

Figure 7. Hepatocytes are the primary site of E11 replication in the liver. (A) C57BI/6 (WT), 645 $\mathrm{hFcRn}^{\mathrm{Tg} 32}$, IFNAR ${ }^{-/}$, or $\mathrm{hFcRn}{ }^{\mathrm{Tg} 32}$ IFNAR $^{-/-}$adult animals were IP inoculated with $10^{4} \mathrm{PFU}$ of E11 
and sacrificed 72 hours post inoculation. Immunohistochemistry for E11 using an antibody recognizing the VP1 capsid protein from the liver of a representative adult animal of each genotype is shown. Black arrows denote positive staining. (B) Schematic of the hybridization chain reaction (HCR) protocol used adapted from the Molecular Instruments HCR v3.0 protocol and created with BioRender.com. (C) HCR of hFcRn ${ }^{T g 32}$-IFNAR ${ }^{-1-}$ adult animals at the indicated dpi using probes against the E11 genome (green) and albumin (red). White boxes denote areas zoomed at bottom. Scale bars shown at bottom right (100 $\mu \mathrm{m}$ at top and $20 \mu \mathrm{m}$ at bottom). Three unique fields were captured and colocalization between VRNA and albumin quantified, as 655 indicated in the text. 
Table 1

Probes used to detect echovirus RNA

\begin{tabular}{|l|l|l|}
\hline $\begin{array}{l}\text { Probe } \\
\text { Pair }\end{array}$ & & \\
\hline B4P1 & $\begin{array}{l}\text { CCTCAACCTACCTCCAAC } \\
\text { AATTTGTGTTGATACTTGCGCTCCCAT }\end{array}$ & $\begin{array}{l}\text { TCAAGCCGGTTTCATGCGCACCGG } \\
\text { TATTCTCACCATATTCGCTTC }\end{array}$ \\
\hline B4P2 & $\begin{array}{l}\text { CCTCAACCTACCTCCAACAAC TG } \\
\text { CCTATTTGCCGAGTTGGATGC }\end{array}$ & $\begin{array}{l}\text { TGAACTTACCAGGGTCTTGTGAAAA } \\
\text { ATTCTCACCATATTCGCTTC }\end{array}$ \\
\hline B4P3 & $\begin{array}{l}\text { CCTCAACCTACCTCCAACAATGTC } \\
\text { ACTGTACCCACACTCTTCAGC }\end{array}$ & $\begin{array}{l}\text { AGTTACCTAGTGTTATGGATCGCA } \\
\text { CATTCTCACCATATTCGCTTC }\end{array}$ \\
\hline B4P4 & $\begin{array}{l}\text { CCTCAACCTACCTCCAACAAT GGC } \\
\text { CTCATTGTCTTTCAGGTACTC }\end{array}$ & $\begin{array}{l}\text { CAGGGTGGGTTGGTTGATCTTCAG } \\
\text { CATTCTCACCATATTCGCTTC }\end{array}$ \\
\hline B4P5 & $\begin{array}{l}\text { CCTCAACCTACCTCCAACAAC } \\
\text { CGGGAATTTCCACCACCACCCGGG }\end{array}$ & $\begin{array}{l}\text { CGAAGAGCCCCATATCTTTTAGGG } \\
\text { CATTCTCACCATATT CGCTTC }\end{array}$ \\
\hline B4P6 & $\begin{array}{l}\text { CCTCAACCTACCTCCAACAACCTG } \\
\text { ATGGAATTAGATGCATTACA }\end{array}$ & $\begin{array}{l}\text { CCGGTACACAGACCACTAGCAAGC } \\
\text { AATTCTCACCATATTCGCTTC }\end{array}$ \\
\hline B4P7 & $\begin{array}{l}\text { CCTCAACCTACCTCCAACAAA } \\
\text { GAATTTCTTAGCGGTCTCCCCCTC }\end{array}$ & $\begin{array}{l}\text { TGTTGGTCCCATTTGTGCTGGTAG } \\
\text { AATTCTCACCATATTCGCTTC }\end{array}$ \\
\hline B4P8 & $\begin{array}{l}\text { CCTCAACCTACCTCCAACAAAATT } \\
\text { TATCCACTGATGTGGGTATAT }\end{array}$ & $\begin{array}{l}\text { CGATGGTGGCGCAGTTATTGGTGC } \\
\text { GATTCTCACCATATTCGCTTC }\end{array}$ \\
\hline B4P9 & $\begin{array}{l}\text { CCTCAACCTACCTCCAACAAGTAC } \\
\text { AAAGGGAATAATCATTAGTGT }\end{array}$ & $\begin{array}{l}\text { TGGATGAATCTGAAGAATAGTCTA } \\
\text { AATTCTCACCATATTCGCTTC }\end{array}$ \\
\hline B4P10 & $\begin{array}{l}\text { CCTCAACCTACCTCCAACAAATCC } \\
\text { TTGCAATGAGGTTGAGAGCCT }\end{array}$ & $\begin{array}{l}\text { TGCTACCCGGTGTATTCATGACAG } \\
\text { GATTCTCACCATATTCGCTTC }\end{array}$ \\
\hline
\end{tabular}

Table 2

Probes used to detect mouse albumin RNA

\begin{tabular}{|c|c|c|}
\hline \multicolumn{3}{|l|}{$\begin{array}{l}\text { Probe } \\
\text { Pair }\end{array}$} \\
\hline & $\begin{array}{l}\text { GAGGAGGGCAGCAAACGG AA } \\
\text { GAGGAGGAGGAGAAAGGTTACCCAC }\end{array}$ & $\begin{array}{l}\text { CCTGGAAAAAGCAGAGCCGGAGACG } \\
\text { TA GAAGAGTCTTCCTTTACG }\end{array}$ \\
\hline B1P2 & $\begin{array}{l}\text { GAGGAGGGCAGCAAACGG AA } \\
\text { TGCTCATCGTATGAGCATTTCTGGA }\end{array}$ & $\begin{array}{l}\text { TCTGTTACTTCCTGCACTAATTTGG } \\
\text { TA GAAGAGTCTTCCTTTACG }\end{array}$ \\
\hline B1P3 & $\begin{array}{l}\text { GAGGAGGGCAGCAAACGG AA } \\
\text { TCACGGAGGTTTGGAATGGCACACA }\end{array}$ & $\begin{array}{l}\text { CAGCAGTCAGCCAGTTCACCATAGT } \\
\text { TA GAAGAGTCTTCCTTTACG }\end{array}$ \\
\hline B1P4 & $\begin{array}{l}\text { GAGGAGGGCAGCAAACGG AA } \\
\text { GGCATAGAAATAAGGATGTCTTCTG }\end{array}$ & $\begin{array}{l}\text { CTGCTCAGCATAGTAAAGAAGTTCT } \\
\text { TA GAAGAGTCTTCCTTTACG }\end{array}$ \\
\hline B1P5 & $\begin{array}{l}\text { GAGGAGGGCAGCAAACGG AA } \\
\text { CACTCCTTGTTGACTTTGGTCAGGT }\end{array}$ & $\begin{array}{l}\text { GCGCATTCCAGCAGGTCACCATGGC } \\
\text { TA GAAGAGTCTTCCTTTACG }\end{array}$ \\
\hline B1P6 & $\begin{array}{l}\text { GAGGAGGGCAGCAAACGG AA } \\
\text { CTTGCACACTTCCTGGTCCTCAACA }\end{array}$ & $\begin{array}{l}\text { GAAGACATCCTTGGCCTCAGCATAG } \\
\text { TA GAAGAGTCTTCCTTTACG }\end{array}$ \\
\hline B1P7 & $\begin{array}{l}\text { GAGGAGGGCAGCAAACGG AA } \\
\text { GCTCTTCTACAAGAGGCTGAAATTC }\end{array}$ & $\begin{array}{l}\text { CACAGTTGGTTTTGACCAAGTTCTT } \\
\text { TA GAAGAGTCTTCCTTTACG }\end{array}$ \\
\hline B1P8 & $\begin{array}{l}\text { GAGGAGGGCAGCAAACGG AA } \\
\text { AGACAGATAGTCTTCCACACAAGGC }\end{array}$ & $\begin{array}{l}\text { CAGCAGACACACACGGTTCAGGATT } \\
\text { TA GAAGAGTCTTCCTTTACG }\end{array}$ \\
\hline B1P9 & $\begin{array}{l}\text { GAGGAGGGCAGCAAACGG AA } \\
\text { TCTCAGCTTTAAACTCTTTGGGGAC }\end{array}$ & $\begin{array}{l}\text { TGCAGATATCAGAGTGGAAGGTGAA } \\
\text { TA GAAGAGTCTTCCTTTACG }\end{array}$ \\
\hline
\end{tabular}


bioRxiv preprint doi: https://doi.org/10.1101/2020.09.24.312058; this version posted September 24, 2020. The copyright holder for this preprint (which was not certified by peer review) is the author/funder. All rights reserved. No reuse allowed without permission.

\begin{tabular}{|l|l|l|}
\hline B1P10 & GAGGAGGGCAGCAAACGG AA & TCATGTCTTTTTTTCTCAGGGTAGC \\
& GAGAAGGTTGTGGTTGTGATTGT & TA GAAGAGTCTTCCTTTACG \\
\hline
\end{tabular}


Supplemental Figure 1

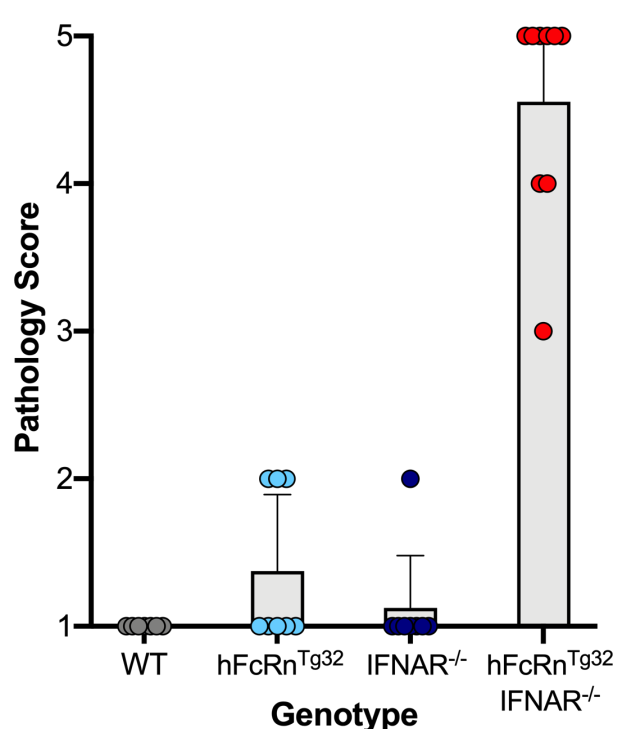

Supplemental Figure 1. WT (grey, 7 animals), hFcRn ${ }^{T g 32}$ (light blue, 8 animals), IFNAR ${ }^{-/-}$(dark blue, 8 animals), and $\mathrm{hFcRn}{ }^{\mathrm{Tg} 32}$-IFNAR ${ }^{-/-}$(red, 6 animals) adult mice were inoculated with $\mathrm{E} 11$ by the IP route and sacrificed 72 hours post inoculation. H\&E sections were scored blinded to genotype based on severity of pathology using the following descriptors-1: retention of normal architecture and cord pattern of liver cells, 2: Immune infiltration, 3: spotty/random hepatocytolysis, 4: punctate aggregates of hepatocyte necrosis/death, and 5: confluent areas of hepatocyte necrosis and death. 


\section{Supplemental Figure 2}

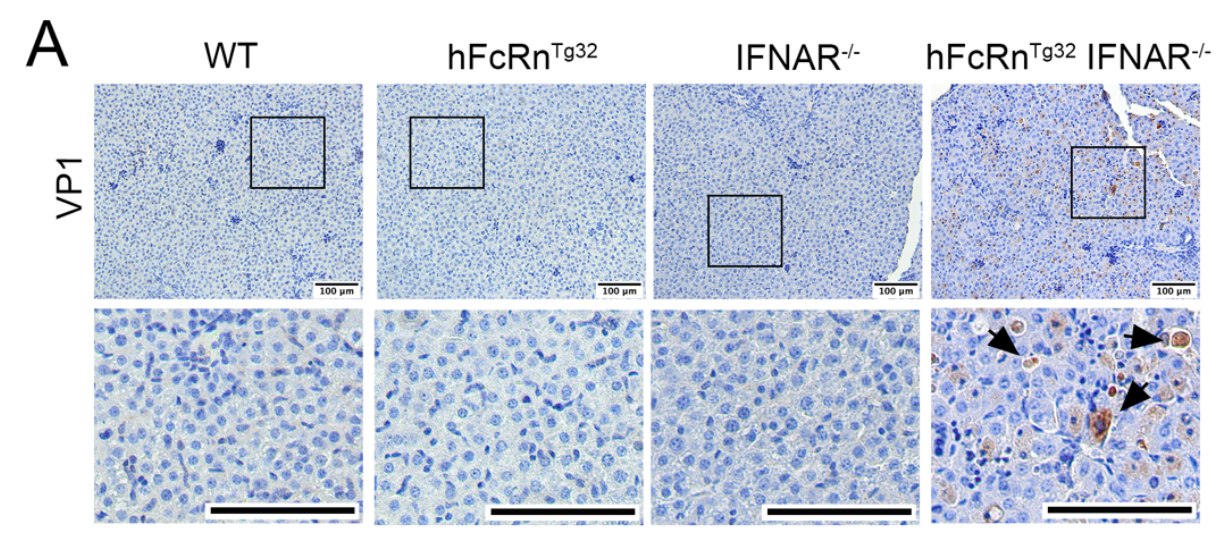

Supplemental Figure 2. WT, hFcRn ${ }^{T g 32}, \mathrm{IFNAR}^{-/-}$, and $\mathrm{hFcRn}{ }^{\mathrm{Tg} 32}$-IFNAR suckling mice were inoculated with E11 by the IP route and sacrificed 72 hours post-inoculation. Shown are representative images from immunohistochemistry for E11 using an antibody recognizing the VP1 capsid protein from the livers of a representative animal of each genotype. 